\title{
Reconstructing the Great Recession
}

\author{
Michele Boldrin, Carlos Garriga, Adrian Peralta-Alva, and Juan M. Sánchez
}

This article uses dynamic equilibrium input-output models to evaluate the contribution of the construction sector to the Great Recession and the expansion preceding it. Through production inter-

linkages and demand complementarities, shifts in housing demand can propagate to other economic sectors and generate a large and sustained aggregate cycle. According to our model, the housing boom (2002-07) fueled more than 60 percent and 25 percent of employment and GDP growth, respectively. The decline in the construction sector (2007-10) generates a drop in total employment and output about half of that observed in the data. In sharp contrast, ignoring interlinkages or demand complementarities eliminates the contribution of the construction sector. (JEL E22, E32, O41)

Federal Reserve Bank of St. Louis Review, Third Quarter 2020, 102(3), pp. 271-311.

https://doi.org/10.20955/r.102.271-311

\section{INTRODUCTION}

With the onset of the Great Recession, U.S. employment and gross domestic product (GDP) fell dramatically and then took a long time to return to their historical trends. There is still no consensus about what exactly made the recession so deep and the subsequent recovery so slow. In this article we evaluate the role played by the construction sector in driving the boom and bust of the U.S. economy during 2001-13.

The construction sector represents around 5 percent of total employment, and its share of GDP is about 4.5 percent. Mechanically, the macroeconomic impact of a shock to the construction sector should be limited by these figures; we claim it is not. Rather, we claim one reason why the Great Recession was particularly deep and persistent is that the construction sector and housing consumption are strongly interconnected to the rest of the economy.

Michele Boldrin is professor of economics at Washington University in St. Louis. Carlos Garriga is a vice president and economist at the Federal Reserve Bank of St. Louis. Adrian Peralta-Alva is a senior economist at the International Monetary Fund. Juan M. Sánchez is an assistant vice president and economist at the Federal Reserve Bank of St. Louis.

The authors are grateful for the stimulating discussions with Morris Davis; Bill Dupor; Ayse Imrohoroglu; Rody Manuelli; Alex Monge-Naranjo; Alp Simsek; Jorge Roldos; Paul Willen; and the seminar participants at the Bank of Canada, Southern Methodist University, International Monetary Fund, 2012 Wien Macroeconomic Workshop, 2012 ITAM Summer Camp in Macroeconomics, 2012 SED, 2015 GBUREES, Stony Brook, and Queens College CUNY. Constanza Liborio, James D. Eubanks, and You Chien provided excellent research assistance.

(c) 2020, Federal Reserve Bank of St. Louis. The views expressed in this article are those of the author(s) and do not necessarily reflect the views of the Federal Reserve System, the Board of Governors, or the regional Federal Reserve Banks. Articles may be reprinted, reproduced, published, distributed, displayed, and transmitted in their entirety if copyright notice, author name(s), and full citation are included. Abstracts, synopses, and other derivative works may be made only with prior written permission of the Federal Reserve Bank of St. Louis. 
Such linkages are important at the production stage (purchases of intermediate goods) but also at the final consumption stage (broad demand complementarities).

Our vision of how a shock to the demand for housing travels to the rest of the economy is the following. In response to a demand-driven housing boom, the construction sector leads the rest of the economy by fueling an expansion through its purchases of inputs. The expansion generates an increase in consumption (housing and nonhousing) as well as investment (residential and capital). This continues either until a new steady state is reached or, as in the historical case we study, a sudden drop in housing demand generates a decline in construction output. This translates into a general reduction of demand (for intermediate inputs and complementary consumption goods), thereby propagating and magnifying, again, the negative sectoral shock. Further, a sudden drop in the demand for housing also generates a slow recovery because the excessive inventory of housing units takes a long time to be absorbed, hence the particularly long delay in the aggregate recovery.

In the empirical analysis, we construct measures of sectoral interlinkages (multipliers) and show that the construction sector is one of the most interconnected in the economy. We use this to quantify the contribution of the construction sector during the period 2002-13 and estimate it to have been unusually large. Construction is capable of accounting for about 52 percent of the decline in total employment and 35 percent of the decline in aggregate gross output. Eliminating the production multipliers weakens the impact on total employment to 20.8 percent and on gross output to 19.3 percent.

In a simplified version of the model, we illustrate the importance of production interlinkages and demand complementarities. This exercise provides a set of sufficient conditions under which the presence of interlinkages generates larger effects in aggregate employment and output than in their absence. The algebra indicates that, for the amplification effect to exist, the sectoral interlinkages must be asymmetric, with the construction sector buying relatively more inputs from the rest of the economy than vice versa. This condition is supported-by more than two orders of magnitude-by estimates from the U.S. input-output table from the Bureau of Economic Analysis (BEA). To generate a multiplier effect via interlinkages, it is also necessary to have an elasticity of substitution between housing and consumption goods lower than 1. $\frac{1}{}$ With an elasticity of substitution larger than 1 , a decline in housing demand generates the reallocation of productive inputs away from the construction sector and a boom in the nonhousing sectors, which may (more than) compensate for the decline due to the supply-side interlinkages. With a unitary elasticity, these two effects cancel out.

One of the limitations of the static model is that it does not allow study of the dynamic adjustment of consumption, residential investment, and productive capital. It also ignores the process of the adjustment of relative prices, and it is not ideal for quantitative purposes. To overcome these limitations, we solve the full dynamic general-equilibrium model numerically. We use that model to answer the following question: If demand for housing shifts exogenously over time to match the observed dynamics of employment in the construction setor, what will happen to the remaining macro quantities and prices?

Our simulations indicate that, in the presence of sectoral interlinkages and consumption complementarities, the size of the boom-bust cycle in total employment and output is sub- 
stantially larger and more coherent with historical observations than otherwise. During the demand-driven housing boom, both sectors in our model expand and contribute to the growth of output and employment, by 2 percent and 2.5 percent, respectively. During the housing bust, the decline in output is 3.3 percent and in total employment is 3.8 percent. The model also captures the leading role of construction during booms and busts (see Leamer, 2007) and the comovement with nonhousing expenditures and investment. Further, the separation of productive capital and residential structures, together with the irreversibility constraints, introduces an asymmetry between expansions and recessions similar to that observed by many previous researchers and that is traditionally hard to obtain in most real business cycle models. $\frac{3}{}$ As in the theoretical exercise, the dynamic quantitative simulations show that reducing the importance of either the sectoral interlinkages or the demand complementarities weakens the transmission mechanism. Moreover, the model without linkages also fails to capture the lead-lag pattern of housing and consumption expenditures observed in the data. These results indicate that modeling production linkages provides a quantitatively relevant transmission channel.

The burst of the real estate "bubble" might have substantially lowered potential output and created a substantial "displacement effect," for both labor and capital, which took quite some time to absorb. Some researchers have referred to this displacement effect as a worsening of labor frictions. For example, Arellano, Bai, and Kehoe (2019) and Ohanian and Raffo (2012) attribute the Great Recession primarily to this factor. Since our model captures significant declines in employment and output in the absence of such frictions, we also perform a business cycle accounting exercise on simulated data from the model. Through the lens of the one-sector neoclassical growth model, the presence of intersectoral linkages, movements in relative prices, and shifts in housing demand can be interpreted as "distortions." Business cycle accounting would attribute the recession generated in the model to the labor wedge. In our model, the magnitude of the worsening of the labor wedge is about 62 percent of the total change observed in the data. Importantly, in both our model and the data, the worsening is due to the consumer side of the labor wedge and not to differences between wages and the marginal product of labor.

Obviously, the fluctuations of the construction sector cannot fully account for the dynamics of employment and output since 2002. Other relevant factors not incorporated into the analysis are important. Many suggest (Black, 1995; Hall, 2011; and Kocherlakota, 2012) that high interest rates could be responsible for the slow recovery. These authors argue that even in models with perfect competition and price flexibility (i.e., lacking the typical frictions of New-Keynesian business cycle models), too-high interest rates may result in substantially lower levels of output and employment. Since some interest rates appear to be currently constrained by the zero lower bound, such analyses appear particularly pertinent. Others argue that the level of uncertainty (Bloom, 2009, and Arellano, Bai, and Kehoe, 2019), government policies (Herkenhoff and Ohanian, 2011), and excessive debt overhang in the economy (Garriga, Manuelli, and Peralta-Alva, 2019; Herkenhoff and Ohanian, 2012; and Kehoe, Ruhl, and Steinberg, 2013) may be responsible for the lackluster recovery. Our exercise is silent with respect to these factors. 
The remainder of the article is organized as follows. Section 2 connects our work with the related literature. Section 3 evaluates the importance of production multipliers first in the data, using the input-output tables of the U.S. economy, and then theoretically, using a stylized two-sector model. Section 4 presents the quantitative multisector model, illustrates the key mechanism at work in the analysis, and quantifies the importance of production linkages and demand complementarities. Section 6 compares the implications of the model in terms of business cycle accounting methodology, and Section 7 offers some concluding comments.

\section{RELATED LITERATURE}

There is a large literature studying the connection between housing and the macroeconomy,, 4 for example, Gervais (2002), Campbell and Hercowitz (2005), Leamer (2007), Fisher (2007), and Davis and Van Nieuwerburgh (2015). Most of these papers explore the effects of housing at the traditional business cycle frequency, ignoring large swings in growth rates as in the case of the Great Recession and the precedent boom. For example, Davis and Heathcote (2005) study the comovement of residential and nonresidential investment in a dynamic multisector model with interlinkages and unitary elasticity of substitution between housing and other goods. Our results show that intersectorial production linkages have large propagation and magnification effects on most macroeconomic variables and that these effects are larger in the presence of demand complementarities.

A small strand of the growth-theoretical literature has long argued that asymmetries in the input-output structure of multisectoral neoclassical models amplify the effect of sectoral shocks and may even generate endogenous cycles for appropriate configurations of the parameters, for example, Benhabib and Nishimura (1979), Boldrin and Deneckere (1990), and Long and Plosser (1983). This theoretical theme has recently seen a revival in a growing literature, both theoretical and applied, stressing that the intersectoral composition of the production sector is an important source of propagation of idiosyncratic sectoral shocks (i.e., Horvath, 1998 and 2000; Carvalho, 2010; Foerster, Sarte, and Watson, 2011; Gabaix, 2011; Acemoglu et al., 2012; Carvalho and Gabaix, 2013; Caliendo et al., 2014; Acemoglu, Ozdaglar, and TahbazSalehi, 2015; and Atalay, Dratzburg, and Wan, 2018). $\frac{5}{\text { Th }}$ This literature focuses on idiosyncratic technological shocks affecting the shape of the production possibility frontier and thereby generating movements of aggregate output. These sectoral supply shocks have been proved to be an important channel through which local perturbations may lead to aggregate fluctuations, absent any change in the composition of aggregate demand. For our part, we study how, absent any technological variation, sectoral demand shocks may also cause aggregate fluctuations. In the case of the Great Recession, it is hard to identify a specific "sectoral production possibility shifter," while there clearly was a dramatic drop in the demand for housing. Interestingly, our analysis shows that technological asymmetries-for example, that a one-sector model is a poor representation of the underlying production possibility set-play a crucial role also in the case of demand shocks. It also shows that demand complementarities, largely ignored in the business cycle literature, are in fact quantitatively relevant and should not be ignored. 
Further along the sectoral-aggregate divide, Li and Martin (2014) study the transmission of shocks using dynamic factor methods and explicitly look at input-output linkages. They find that a significant part of traditionally defined aggregate fluctuations are driven by "sectorspecific shocks." In the case of the Great Recession, more than half of aggregate volatility is accounted for by an additional aggregate shock—which they label the "wedge factor" - emerging only during this period. Most crucially, and consistently with our bottom line, they find that shocks originating in the construction sector generate the largest spillover effects over time, dominating those of all the other sectors. In our model, the driving force is an exogenous shifter in housing demand that acts like a wedge factor.

There is also an extensive literature that explores the role of financial conditions as drivers of the Great Recession and of the delayed recovery (i.e., Black, 1995, and Bloom, 2009; Christiano Motto, and Rostagno, 2010; Arellano, Bai and Kehoe, 2019; Gertler and Karadi, 2011; Hall, 2011; Jones, Midrigan, Philippon, 2018; Kocherlakota, 2012; Jermann and Quadrini, 2012; Brunnermeier and Sannikov, 2013; He and Krishnamurthy, 2019; and Mitman, Kaplan, and Violante, 2020). Most of the literature abstracts from the role of housing during this episode, with a few exceptions. Among them is Garriga, Manuelli, and Peralta-Alva (2019). In their model, an increase in the cost of housing financing generates a collapse of house prices, inducing a recession through deleveraging. Similarly, Martinez, Hatchondo, and Sánchez (2015) use heterogeneous agent models to analyze the aggregate effects of a house price decline and of its propagation to the rest of the economy through household balance sheets and housing defaults. Iacoviello and Pavan (2013) argue that a tightening of household budgets, due to the drop in real estate wealth, induced a sharp decline in aggregate consumption. Rognlie, Shleifer, and Simsek (2018) explore the aggregate effect of insufficient housing demand resulting from a period of overbuilding. Our article is complementary to this literature because, once again, we take as granted the drop in housing demand and then study its supply-side propagation due to sectoral interlinkages.

\section{CONSTRUCTION IN AN INPUT-OUTPUT ECONOMY}

This section first provides empirical evidence and then a simple theoretical evaluation of the importance of interlinkages. The data analysis places special attention on the Great Recession but also uses detailed U.S. sectoral input-output data for the period 1990-2013. The theoretical framework provides a set of sufficient conditions for the amplification mechanism to work. $\underline{6}$

\subsection{Construction and Aggregate Fluctuations: 1990-2013}

For the analysis of economic fluctuations, it is common to use aggregate data for the whole postwar period. Unfortunately, the current availability of uniform input-output data is limited to the years 1990-2014. According to the BEA, the U.S. economy has experienced three recessions (1990-91, 2000-01, and 2007-09) during that interval of time. To evaluate the direct contribution of the construction sector to each episode, Table 1 summarizes the changes in employment and real income for the construction and private sectors. We measure the direct contribution of construction as the ratio of the change in construction to each total 


\section{Table 1}

\section{The Role of Construction in the Past Three Recessions}

\begin{tabular}{|c|c|c|c|c|}
\hline \multirow[b]{2}{*}{ Recessions } & \multicolumn{2}{|c|}{ Employment (millions) } & \multicolumn{2}{|c|}{ Real income (billions of dollars) } \\
\hline & $\begin{array}{c}\text { Construction } \\
\text { sector }\end{array}$ & $\begin{array}{l}\text { Private } \\
\text { sector }\end{array}$ & $\begin{array}{c}\text { Construction } \\
\text { sector }\end{array}$ & $\begin{array}{l}\text { Private } \\
\text { sector }\end{array}$ \\
\hline \multicolumn{5}{|l|}{ 1990-91 } \\
\hline Peak, 1990:Q3 & 5.24 & 109.6 & 346.0 & 7,455 \\
\hline Trough, 1991:Q1 & 4.93 & 108.7 & 320.6 & 7,400 \\
\hline Difference & -0.31 & -0.87 & -25.4 & -54.9 \\
\hline Percent accounted for by construction & \multicolumn{2}{|c|}{35.4} & \multicolumn{2}{|c|}{46.3} \\
\hline \multicolumn{5}{|l|}{$2000-01$} \\
\hline Peak, 2000:Q1 & 6.84 & 132.6 & 610.4 & 10,870 \\
\hline Trough, 2001:Q4 & 6.79 & 131.0 & 598.7 & 10,629 \\
\hline Difference & -0.05 & -1.55 & -11.70 & -241.1 \\
\hline Percent accounted for by construction & \multicolumn{2}{|c|}{3.3} & \multicolumn{2}{|c|}{4.9} \\
\hline \multicolumn{5}{|l|}{ 2007-09 } \\
\hline Peak, 2007:Q4 & 7.53 & 137.9 & 682.3 & 12,586 \\
\hline Trough, 2009:Q2 & 6.09 & 131.0 & 540.5 & 11,852 \\
\hline Difference & -1.4 & -6.9 & -141.8 & -734.0 \\
\hline Percent accounted for by construction & \multicolumn{2}{|c|}{20.3} & \multicolumn{2}{|c|}{19.3} \\
\hline
\end{tabular}

change. The top panel of Table 1 reminds us that the 1990-91 recession was mild: Between the peak of 1990:Q3 and the trough of 1991:Q1, for the private sector, employment and income each declined by less than 1 percent. In relative terms, the declines in the construction sector were sizeable: slightly less than 6 percent for employment and more than 7 percent for income. The middle panel of Table 1 shows the recession that started in 2000:Q1 and ended in 2001:Q4. This recession was slightly more severe: for the private sector, employment fell by more than 1 percent and income by more than 2 percent. However, the declines in the construction sector were almost negligible and the shares of the aggregate declines they accounted for were small.

The Great Recession started in 2007:Q4 and lasted until 2009:Q2. During this period, total employment decreased by roughly 7 million jobs. Table 1 shows that the direct contributions of the drops in construction employment and real income were 20.3 percent and 19.3 percent, respectively. This recession was dramatically bigger than the previous two, and the size of the drop in employment was 18.6 percent, not 5.9 percent as in 1990-91 or 0.7 percent as in 2000-01.

These calculations ignore the fact that construction leads the cycle and that during the Great Recession this industry went into recession 18 months before the overall economy. Measuring the decline from the perspective of the construction cycle shows that employment fell from 7.7 million (2006:Q3) to 5.5 million (2011:Q1) and recovered little thereafter. Figure 1 


\section{Figure 1}

\section{The Construction Sector During the Great Recession}

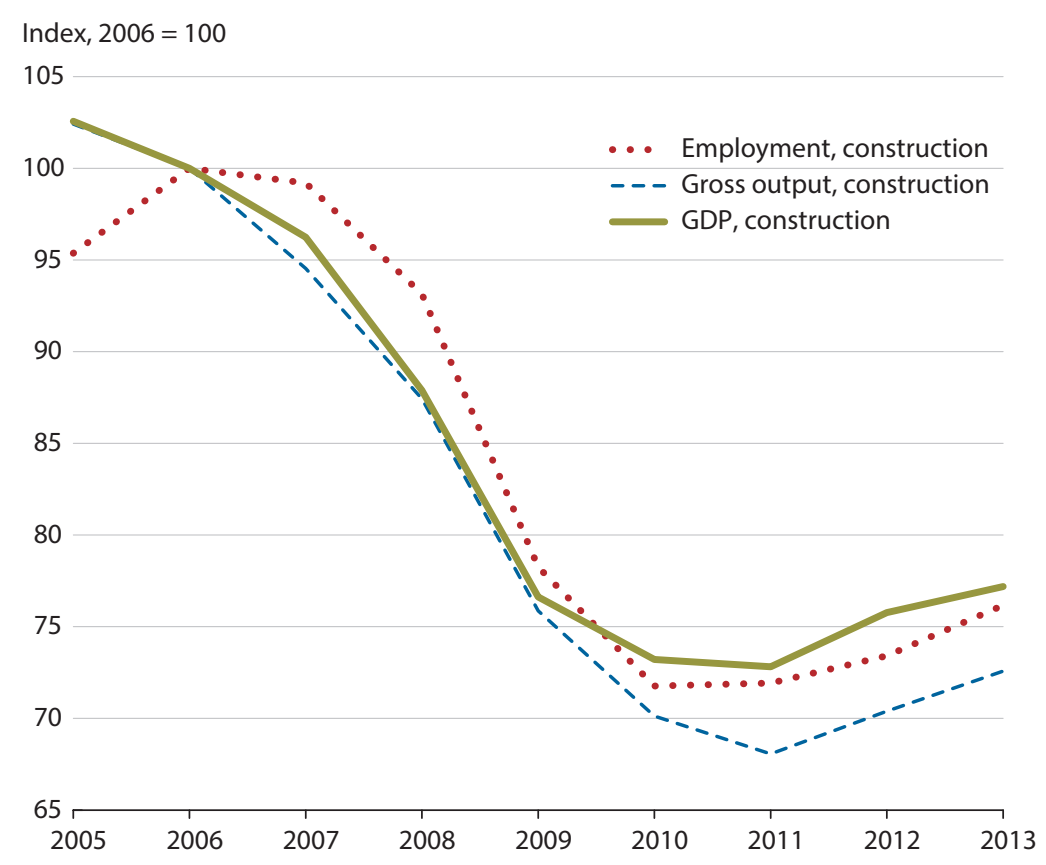

SOURCE: BEA.

shows that employment, gross output, and GDP in the construction sector each dropped about 30 percent, whereas Table 1 infers employment dropped by 18.6 percent.

\subsection{Evidence and Implications of Production Interlinkages}

This subsection uses input-output data to provide a rough estimate of the role of interlinkages in the aggregate amplification of sectoral demand shocks during the cycle leading up to the Great Recession. Despite its relatively small size, the contribution of the construction sector to the Great Recession was a combination of two factors: the large size of the shocks affecting the sector and the sector's strong interlinkages with suppliers. One way of measuring sectoral interlinkages is through the purchases of a sector from other sectors, expressed as a percentage of the total output of the latter. For the period 1990-2013, these calculations are reported in Figure 2.

These numbers show by how much the total demand for the (gross) output of these sectors would immediately decrease if construction demand vanished. For instance, the total demand for the manufacturing sector would immediately decrease by 7 percent if the construction sector vanished. This measures only the direct effect: Because each sector purchases goods and services from other sectors as inputs, the process continues-virtually for an infinite number of steps-until it converges, thereby inducing a "production multiplier" effect. This multiplier 


\section{Boldrin, Garriga, Peralta-Alva, Sánchez}

\section{Figure 2}

\section{Purchases from Other Sectors}

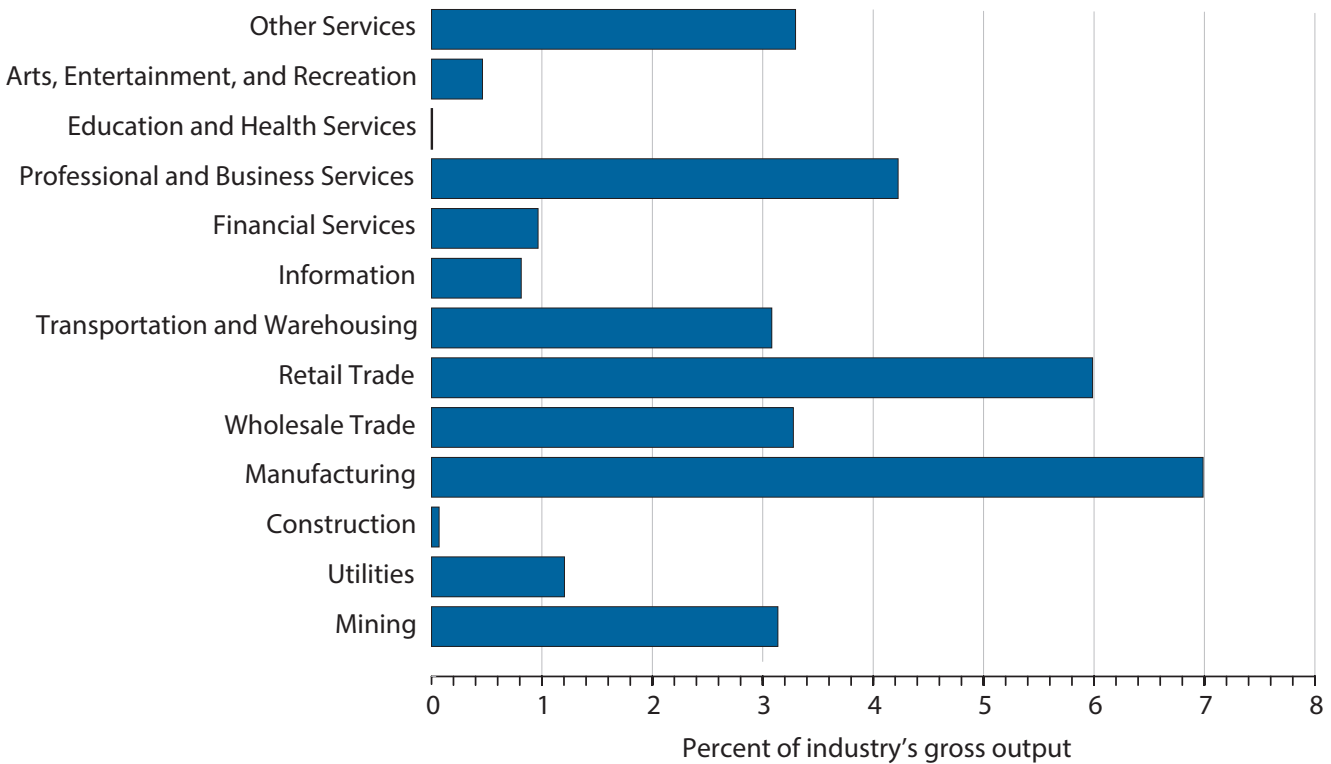

SOURCE: Use matrix from the 2006 BEA input-output tables.

\section{Figure 3}

\section{Sectors' Multipliers}

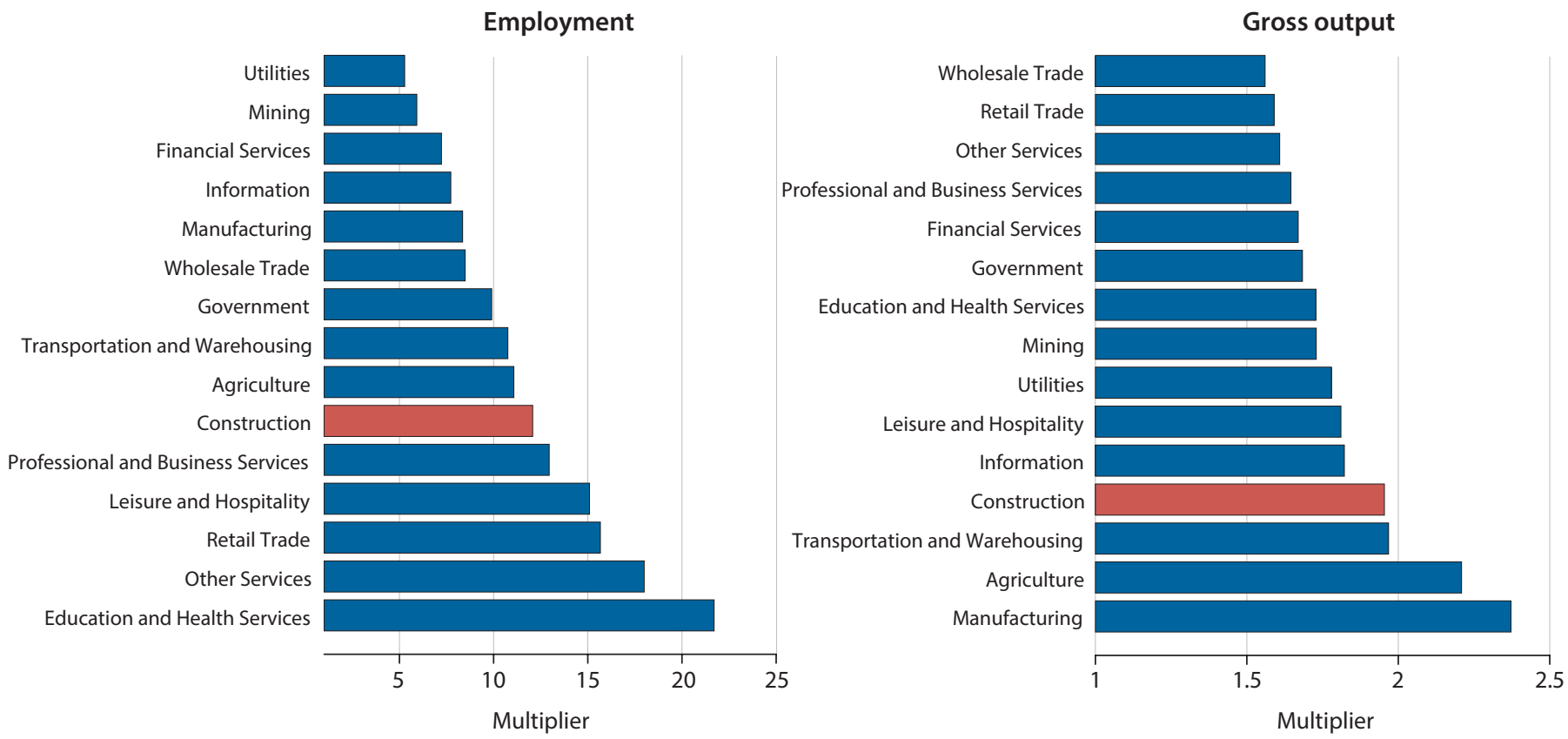

SOURCE: Use matrix from the 2006 BEA and BLS input-output tables. 


\section{Figure 4}

\section{The Construction Sector's Contribution to the Dynamics of Employment and Gross Output}
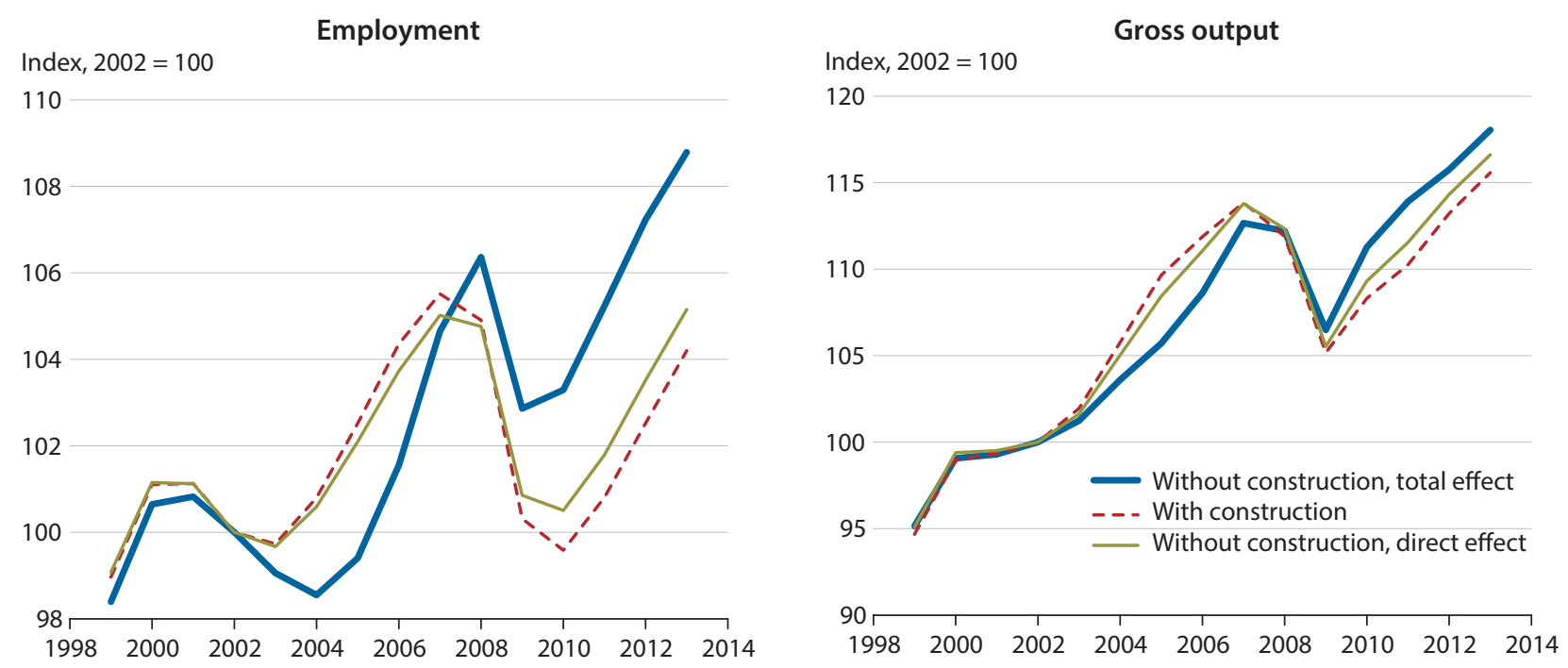

SOURCE: Authors' calculations using BEA and BLS requirements tables.

can be used to calculate the total effect of a sectoral shock on the rest of the economy. Figure 3 ranks sectors according to the size of their multipliers in terms of gross output and employment.

In terms of gross output, the two sectors with the largest multipliers are manufacturing (2.4) and agriculture (2.3). Construction has the fourth largest production multiplier: A \$1 decline in the output of the construction sector generates (absent changes in relative prices and in the composition of final demand) a slightly below $\$ 2$ decline in gross output of all other sectors combined. Recall that the construction sector is larger than the agriculture sector, its final demand much more volatile than those of both the manufacturing and agriculture sectors, and its output composition more homogeneous. In terms of employment, the construction sector also has a relatively large multiplier. It is worth noting that with respect to employment, the multipliers of the manufacturing and agriculture sectors are not as significant as the multiplier for the construction sector. This highlights that the construction sector is important overall because of its employment and gross output multipliers.

Our goal is to understand how significant these multipliers are when it comes to aggregate fluctuations. To this end, we add up the direct and multiplier effects for the construction sector to compute the total effect of construction on the rest of the economy. We use the requirement matrices and compare the actual evolution of U.S. employment and gross output with a counterfactual economy without the construction sector. Figure 4 displays the paths of employment and gross output for the three cases: the actual values and the values without the direct and without the total effects of construction. The difference between these paths is a rough estimate of the construction sector's (direct and total) impact on the aggregate dynamics. When construction is included, total employment increases about 6 percent between 2002 and 2006, 


\section{Figure 5}

\section{Sectoral Changes During the Great Recession: The Data and Input-Output Simulations}

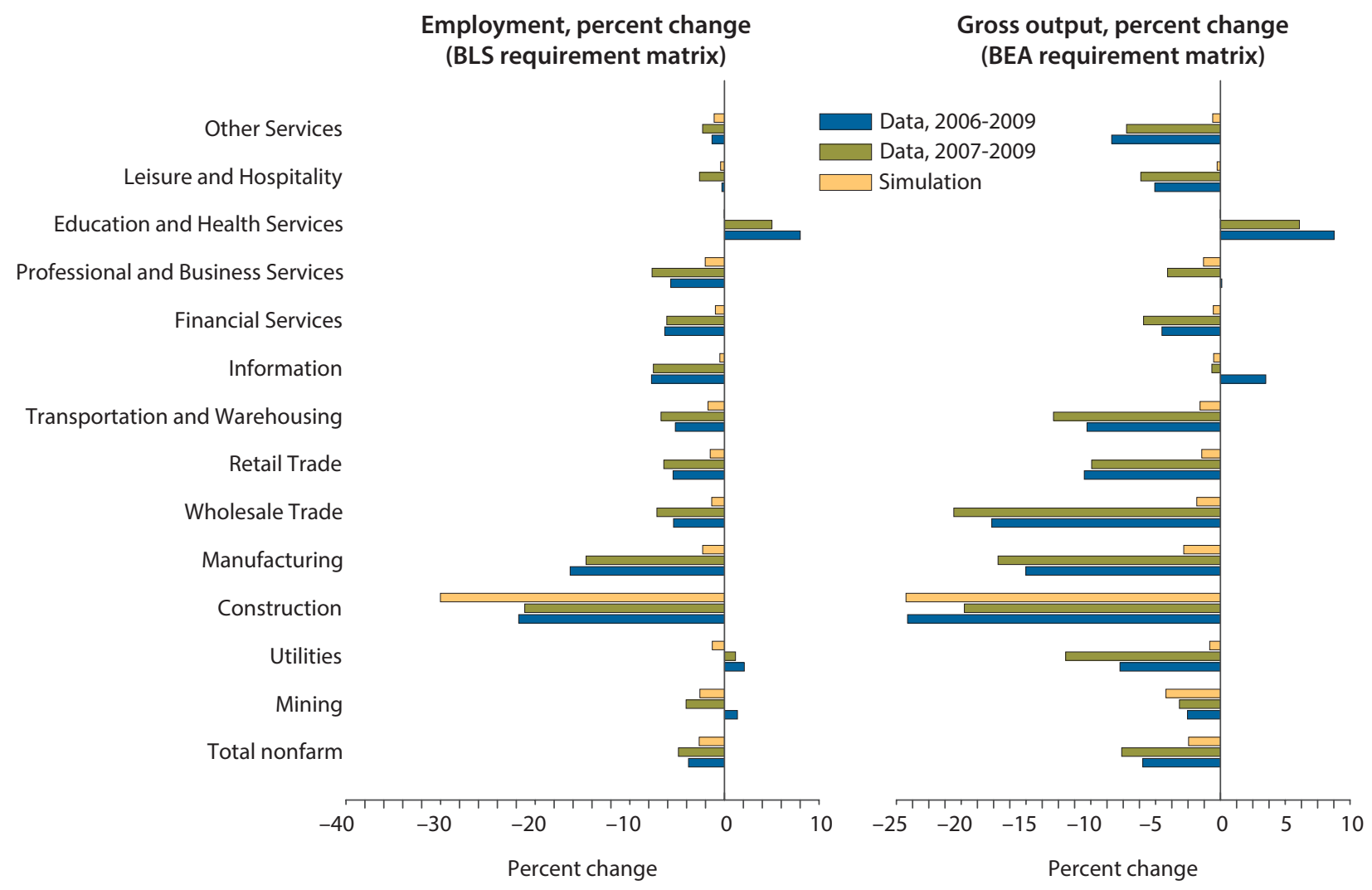

SOURCE: Authors' calculations using BEA data.

which is then entirely lost. In contrast, the economy without a construction sector and with the total effect has a slower recovery from the 2000-01 recession; employment growth picks up only in 2005 and employment destruction starts in 2009. The magnitude of the subsequent decline is half that actually experienced. Unlike in the actual economy, employment starts recovering already in 2010 and in 2012 surpasses the previous peak. This exercise shows that the construction sector contributed greatly to employment growth between 2002 and 2005 and to employment destruction during the Great Recession. A similar, if somewhat weaker, conclusion can be drawn by analyzing the panel for gross output. This simple decomposition reveals that during the Great Recession construction alone may have accounted for 52 percent of the decline in employment and 35 percent of the decline in gross output.

At a more micro level, construction interacts differently with the various sectors in the economy. Therefore, a decline in the activity of the construction sector will have a larger impact on those sectors that sell to it directly as opposed to those that do not. To show this, Figure 5 reports for each sector the actual sectoral declines in employment and gross output, respectively, between 2006-09 and 2007-09 and those estimated using the input-output matrix for 


\section{Figure 6}

\section{Sectoral Changes During the Recovery: The Data and Input-Output Simulations}

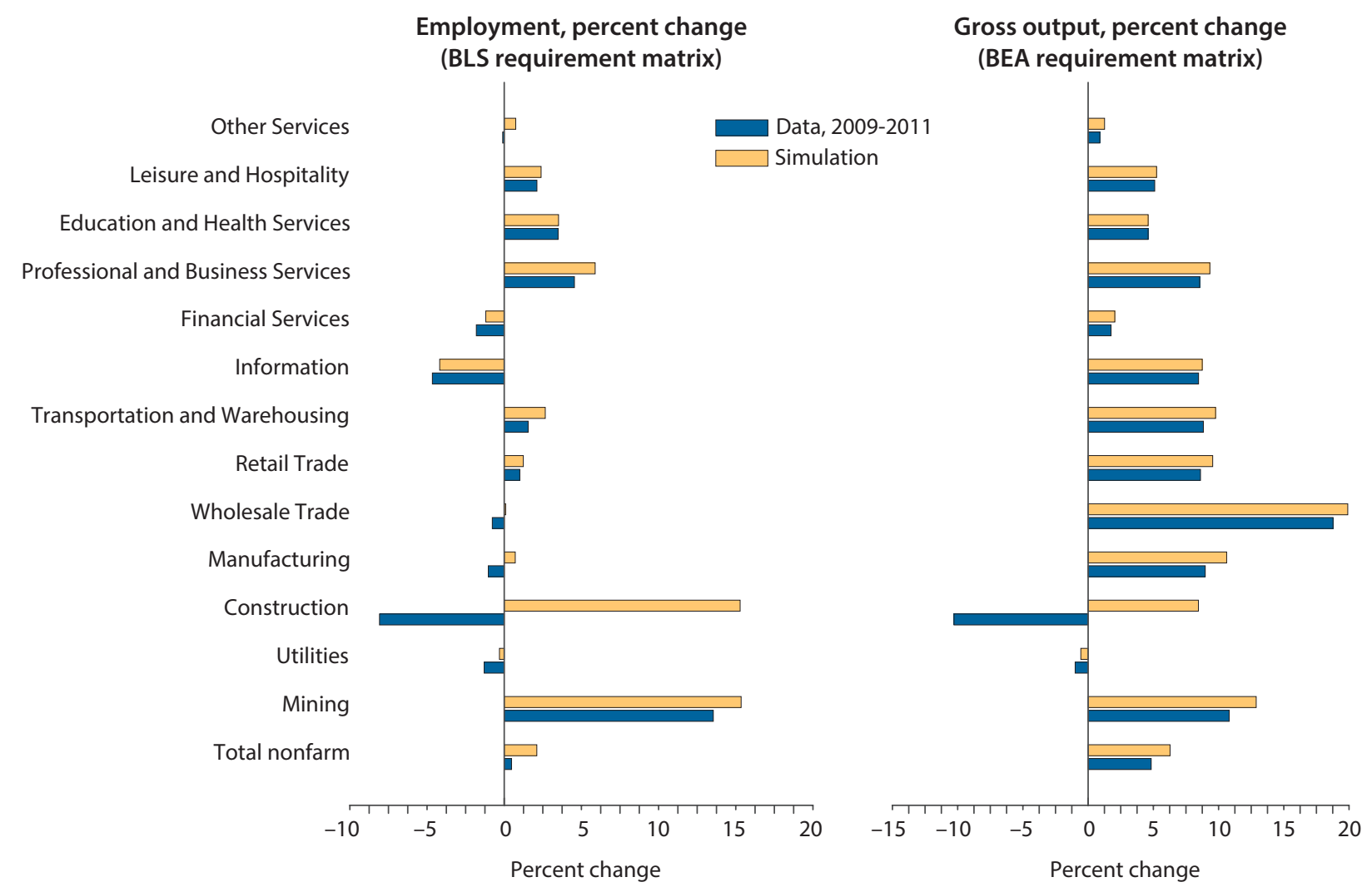

SOURCE: Authors' calculations using BEA data.

2007-09, as a consequence of the observed decline in construction. ${ }^{-}$The blue (2006-09) and green bars (2007-09) in Figure 5 represent the historical percent changes in gross output and employment for 13 industries and for the total economy (total nonfarm). In 2006-09, gross output in the construction sector and in the aggregate (total nonfarm) declined close to 25 percent and 6.2 percent, respectively. Employment in the construction sector decreased by roughly the same amount as gross output, 21.5 percent, while aggregate employment declined by 4.4 percent. The aggregate numbers are slightly larger when considering the period 2007-09. The yellow bars represent the declines attributable to the construction sector on the basis of the input-output multipliers (for gross output and employment, respectively). For example, according to this methodology, the drop in the construction sector accounts for a significant part of the gross output decline in the mining sector, about 68 percent of it, while it accounts for little of the decline in the retail trade sector.

According to this methodology, construction is capable of accounting for about 35 percent of the decline in aggregate gross output and for about 52 percent of the decline in aggregate employment. These numbers contrast with the direct impact estimates that account for 20.3 
percent of the decline in employment and 19.3 percent of the decline income, as shown in Table 1 . The difference between the direct and the total effects of construction is due to the magnifying role of the production interlinkages, and this is what we label the production multiplier.

The construction sector played an important role not only in the Great Recession but also in the subsequent slow recovery. Its contribution can be measured by performing a similar counterfactual for the period 2009-11. Figure 6 shows the simulated growth rates for the 13 sectors and the total economy (nonfarm economy) under the assumption that construction grows from 2009 forward at pre-recession rates. The blue bars display the actual percent changes of gross output and employment, respectively. Between 2009 and 2011, gross output increased by 5 percent and employment increased by roughly 1 percent. The yellow bars represent the counterfactual simulation and show that if construction had grown at its pre-recession levels, total gross output and employment would have increased by 6 percent and 2 percent, respectively. In this scenario, the sectors that would have grown the most in terms of gross output are wholesale trade (20 percent), retail trade (10 percent), mining (13 percent), and transportation and warehousing (11 percent). The differences between the above growth rates and the actual growth rates (blue bars) indicate that the contribution of the construction sector to the dynamics of aggregate employment and output is nontrivial. The next section proposes a simple model of interlinkages that explains the nature of these effects.

\section{THEORETICAL MODEL OF INPUT-OUTPUT LINKAGES}

This section presents a stylized two-sector model with housing and production interlinkages. The model also incorporates the durable consumption goods nature of housing, the presence of a fixed factor in the production of housing services (i.e., land), and the complementarity between consumption of housing services and of all other goods.

\section{1 Households}

Total population size, $N_{t}$, is normalized to 1 . Household preferences are defined by a time-separable utility function, $U\left(c_{t}, \theta_{t} h_{t}, n_{t}\right)$, where $c_{t}$ represents consumption goods, $h_{t}$ represents housing services, and $n_{t}$ represents labor supplied in the market. Housing provides utility, and it is a complement to aggregate consumption. The shifts in housing consumption are driven by adjustments in the parameter $\theta_{t}$. The utility function $U$ satisfies the usual properties of differentiability and concavity. The sequence of utilities is discounted by the term $\beta \in(0,1)$. Housing services are obtained by combining physical structures, $s_{t}$, and land, $l_{t}$, according to $H\left(s_{t}, l_{t}\right)$. The latter is homogeneous of degree 1 and satisfies $H_{i}^{\prime}>0, H_{i}^{\prime \prime}>0$ and $H_{i j}^{\prime \prime}>0$. Housing structures depreciate at a constant rate, $\delta_{s^{\prime}}$. In each period, the numeraire is the spot price of the nonconstruction good. Formally, the representative consumer chooses $\left\{c_{t}, h_{t}, n_{t}, k_{t+1}, s_{t+1}, l_{t+1}\right\}_{t=0}^{\infty}$ to maximize

$$
\begin{gathered}
\max \sum_{t=0}^{\infty} \beta^{t} U\left(c_{t}, \theta_{t} h_{t}, n_{t}\right), \\
\text { s.t. } \quad c_{t}+x_{t}^{k}+p_{t}^{s} x_{t}^{s}=w_{t} n_{t}+r_{t}^{k} k_{t}+p_{t}^{l}\left(l_{t}-l_{t+1}\right)+\pi_{t},
\end{gathered}
$$




$$
\begin{gathered}
h_{t}=H\left(s_{t}, l_{t}\right), \\
x_{t}^{k}=k_{t+1}-\left(1-\delta_{k}\right) k_{t} \geq 0, \\
x_{t}^{s}=s_{t+1}-\left(1-\delta_{s}\right) s_{t} \geq 0 .
\end{gathered}
$$

The maximization is also subject to transversality and no-Ponzi-game conditions. Prices are defined as follows: $p_{t}^{s}$ is the price of infrastructure, $p_{t}^{l}$ is the price of land, $w_{t}$ is the wage rate, and $r_{t}$ is the gross return on capital. To facilitate computing the rental rate for housing services, our specification allows land trading, $l_{t}$, even if in equilibrium there is no trading of land, which is owned by the representative household and inelastically supplied. The term $\pi_{t}$ represents profits from the construction sector. All investment decisions are subject to an irreversibility constraint and have different depreciation rates in the two sectors, construction and nonconstruction.

The relevant first-order conditions of the consumer problem are

$$
\begin{gathered}
\frac{U_{n}\left(c_{t}, \theta_{t} h_{t}, n_{t}\right)}{U_{c}\left(c_{t}, \theta_{t} h_{t}, n_{t}\right)}=w_{t}, \quad \forall t, \\
\frac{U_{c}\left(c_{t}, \theta_{t} h_{t}, n_{t}\right)}{\beta U_{c}\left(c_{t+1}, \theta_{t+1} h_{t+1}, n_{t+1}\right)}=1+r_{t+1}^{k}-\delta_{k}, \quad \forall t,
\end{gathered}
$$

when the irreversibility constraints do not bind, $x_{t}^{k}>0$. The relevant conditions for housing decisions for the case with positive housing investment $\left(x_{t}^{s}>0\right)$ satisfy

$$
\begin{gathered}
\frac{U_{h}\left(c_{t}, \theta_{t} h_{t}, n_{t}\right)}{U_{c}\left(c_{t}, \theta_{t} h_{t}, n_{t}\right)}=R_{t}, \quad \forall t, \\
p_{t}^{s}=\frac{1}{1+r_{t+1}^{k}}\left[R_{t+1} H_{s}\left(s_{t}, l_{t}\right)+p_{t+1}^{s}\left(1-\delta_{s}\right)\right], \\
p_{t}^{l}=\frac{1}{1+r_{t+1}}\left[R_{t+1} H_{l}\left(s_{t}, l_{t}\right)+p_{t+1}^{l}\right],
\end{gathered}
$$

where $R_{t}$ represents the implicit rental price for housing services measured in terms of consumption units. Notice that a no-arbitrage condition holds between investment in land and housing. The last two expressions state that the current cost of purchasing a unit of housing structures (land) equals the future return of housing services derived from the housing capital (land) valued at market prices, plus its capitalization.

\subsection{Nonconstruction Sector}

The model uses a $2 \times 2$ input-output structure: To operate, each sector requires, among other things, that the output of a sector uses intermediate inputs from other sectors as well as 
its own. To capture this fact, we deviate from common practice and write all production functions in terms of gross (as opposed to net, i.e., value-added) output. Capital goods, which are produced in the nonconstruction sector, must be distinguished from the intermediate inputs from the same sector since they last more than one period. In the baseline model, capital goods are used only in the nonconstruction sector for simplicity. Both investments satisfy the putty-clay assumption, which is sector specific.

Formally, let $m^{i, j}$ be the intermediate input produced by sector $i$ and used by sector $j$. The nonconstruction sector operates in a competitive market and uses the technology $A_{t}^{y} F\left(k_{t}, n_{t}^{y}, m_{t}^{y, y}, m_{t}^{s, y}\right)$ to produce its gross output:

$$
Y_{t}=c_{t}+x_{t}^{k}+m_{t}^{y, y}+m_{t}^{y, s}
$$

The production function $F$ has constant returns to scale. The firm's optimization problem is

$$
\begin{gathered}
\pi_{t}^{y}=\max _{k_{t}, n_{t}^{y}, m_{t}^{y, y}, m_{t}^{s, y}} Y_{t}-w_{t} n_{t}^{y}-r_{t}^{k} k_{t}-m_{t}^{y, y}-p_{t}^{s} m_{t}^{s, y}, \quad \forall t, \\
\text { s.t. } \quad Y_{t}=A_{t}^{y} F\left(k_{t}, n_{t}^{y}, m_{t}^{y, y}, m_{t}^{s, y}\right), \quad \forall t,
\end{gathered}
$$

where the price of the nonconstruction sector's output is normalized to 1 . The constant-returnsto-scale assumption implies zero equilibrium profits, $\pi_{t}^{y}=0$, and marginal cost pricing for each input

$$
\begin{gathered}
r_{t}^{k}=A_{t}^{y} F_{1}\left(k_{t}, n_{t}^{y}, m_{t}^{y, y}, m_{t}^{s, y}\right), \\
w_{t}=A_{t}^{y} F_{2}\left(k_{t}, n_{t}^{y}, m_{t}^{y, y}, m_{t}^{s, y}\right), \\
1=A_{t}^{y} F_{3}\left(k_{t}, n_{t}^{y}, m_{t}^{y, y}, m_{t}^{s, y}\right), \\
p_{t}^{s}=A_{t}^{y} F_{4}\left(k_{t}, n_{t}^{y}, m_{t}^{y, y}, m_{t}^{s, y}\right) .
\end{gathered}
$$

\subsection{Construction Sector}

The construction sector is also competitive. Its net output consists of residential structures, purchased by the households, while its gross output also includes structures used as intermediate inputs in both sectors. In the baseline case, purely for simplicity, we assume this sector has a fixed stock of capital; hence its value added is split between the wages of labor and the rent accruing to the owner of the fixed capital stock (the representative household). Implicit in this formulation is a somewhat extreme assumption about the mobility of factors from one sector to another: While labor can move freely, the stock of capital invested in the construction sector is completely immobile (either way), and variations in investment activity have an impact only on the nonconstruction sector. The technology for gross output is represented by

$$
X_{t}^{S}=x_{t}^{s}+m_{t}^{s, s}+m_{t}^{s, y}=A_{t}^{s} G\left(n_{t}^{s}, m_{t}^{s}\left(m_{t}^{s, s}, m_{t}^{y, s}\right)\right)
$$

and exhibits decreasing returns to scale in labor and the intermediate input mix. The function $G(\cdot)$ has a constant elasticity of substitution, and the aggregator of intermediate inputs is homogeneous of degree 1 . The optimization problem of the representative firm is now 


$$
\begin{gathered}
\pi_{t}^{s}=\max _{n_{t}^{s}, m_{t}^{s, s}, m_{t}^{y, s}} p_{t}^{s} X_{t}^{S}-w_{t} n_{t}^{s}-p_{t}^{s} m_{t}^{s, s}-p_{t}^{y} m_{t}^{y, s}, \quad \forall t, \\
\text { s.t. } \quad X_{t}^{S}=A_{t}^{s} G\left(n_{t}^{s}, m_{t}^{s}\left(m_{t}^{s, s}, m_{t}^{y, s}\right)\right), \quad \forall t .
\end{gathered}
$$

The first-order conditions are similar to those of the representative firm in the nonconstruction sector and are not repeated here. Note that because of the presence of a fixed stock of capital, firm profits are not zero in equilibrium in this sector. It is worth emphasizing that $p_{t}^{s}$ reflects the cost of producing new structures. The equilibrium price of a house differs from this value since it depends on the relative value of the structures and land.

\subsection{Competitive Equilibrium}

The competitive equilibrium of this economy is defined as follows:

Competitive Equilibrium: Given a sequence of values $\left\{A_{t}^{y}, A_{t}^{s}, \theta_{t}\right\}_{t=0}^{\infty}$, a competitive equilibrium consists of allocations $\left\{c_{t}, x_{t}^{k}, x_{t}^{s}, l_{t}, n_{t}^{y}, n_{t}^{s}, m_{t}^{s, s}, m_{t}^{y, s}, m_{t}^{y, y}, m_{t}^{s, y}\right\}_{t=0}^{\infty}$ and prices $\left\{w_{t}, r_{t}^{k}, p_{t}^{l}, p_{t}^{s}, r_{t}, R_{t}\right\}_{t=0}^{\infty}$ that satisfy the following:

(i) the household's optimization problem;

(ii) profit maximization in the construction and nonconstruction sectors; and

(iii) the clearing of markets:

(a) the labor market $\left(w_{t}\right)$ :

$$
n_{t}=n_{t}^{y}+n_{t}^{s}, \quad \forall t
$$

(b) the land market $\left(p_{t}^{l}\right)$ :

$$
l_{t}=l_{t-1}=\bar{l}, \quad \forall t
$$

(c) the capital market $\left(r_{t}^{k}\right)$ :

$$
r_{t}^{k}=A_{t}^{y} F_{1}\left(k_{t}, n_{t}^{y}, m_{t}^{y, y}, m_{t}^{s, y}\right), \quad \forall t ;
$$

(d) the nonconstruction output market $\left(p_{t}^{c}=1\right)$ :

$$
c_{t}+x_{t}^{k}+m_{t}^{y, y}+m_{t}^{y, s}=A_{t}^{y} F\left(k_{t}, n_{t}^{y}, m_{t}^{y, y}, m_{t}^{s, y}\right), \quad \forall t ; \text { and }
$$

(e) the construction output market $\left(p_{t}^{s}\right)$ :

$$
x_{t}^{s}+m_{t}^{s, s}+m_{t}^{s, y}=A_{t}^{s} G\left(n_{t}^{s}, m_{t}^{s}\left(m_{t}^{s, s}, m_{t}^{y, s}\right)\right), \quad \forall t .
$$

For a given sequence of housing demand shifters $\left\{\theta_{t}\right\}$ the model endogenously generates time series for all macroeconomic quantities and prices. Before comparing the predictions of the model with the data, it is useful to understand how to characterize the amplification process. This is described in the next subsection. 


\subsection{The Macroeconomic Effects of Production Interlinkages and Demand Complementarities}

To proceed analytically it is necessary to make a number of simplifying assumptions relative to the baseline model: (i) the economy lasts one period, (ii) labor and intermediate goods are the only inputs, and (iii) the share of land in the housing aggregator is zero. The utility index is defined as $U(c, \theta, h, n)$, and the budget constraint of the representative household is $c+p h=w n$, where $w$ is the wage rate and $p$ the price of housing, both measured in units of the nonconstruction good.

Part of the output of the nonconstruction sector, $m_{y}$, is used as an input to produce construction, and part of the output of the construction sector is used to produce nonconstruction goods, $m_{h}$. The gross output flows of the two sectors are $c+m_{y}=Y=A_{y} f\left(n_{y}, \varepsilon_{y} m_{h}\right)$ and $h+m_{h}=H=A_{h} g\left(n_{h}, \varepsilon_{h} m_{y}\right)$, respectively, where $A_{j}$ represents the productivity of sector $j=y, h . \underline{8}$ The $\varepsilon_{j}(j=y, h)$ terms capture the relative importance in sector $j$ of the intermediate inputs from the other sector. Aggregate labor satisfies the restriction $n_{y}+n_{h}=n$. Free mobility implies that the wage rate is the same across sectors.

A competitive equilibrium in this economy is an allocation $\left\{c, h, n_{y}, n_{h}, m_{y}, m_{h}\right\}$ and prices $\{w, p\}$ that solve (i) the optimization problem of the household, (ii) the optimization problem of the firms in each sector, and ( iii) the market-clearing conditions.

As a function of the preferences $(\theta)$ and technology $(\varepsilon)$ parameters, value added in this economy is defined as

$$
V A(\theta, \varepsilon)=c(\theta, \varepsilon)+p(\theta, \varepsilon) h(\theta, \varepsilon)
$$

The goal is to identify conditions under which a shift $\Delta \theta=\theta^{\prime}-\theta$ in the demand for housing has a larger impact on total employment and value added when there are interlinkages $(\varepsilon>0)$ rather than when there are not $(\varepsilon=0)$, that is, the conditions under which we have

$$
\frac{\partial V A(\theta, \varepsilon)}{\partial \theta} \geq \frac{\partial V A(\theta, 0)}{\partial \theta} .
$$

There are three interacting channels through which a change in the demand for housing may affect value added: (i) a direct change in the desired quantities of $c$ and $h$, (ii) a change in their relative prices (and the consequent second-order changes in the quantities demanded), and (iii) a change in the supply of labor due to wealth and price effects. To highlight the difference of this transmission mechanism relative to the recent literature discussed in Section 2 above, the next examples abstract from movements in relative prices due to sectoral shocks. The full quantitative model will also consider changes in relative prices and the related adjustments in quantities.

4.5.1 Example: Leontief Production. A simple way to eliminate the price effects is to consider an economy in which both production functions have fixed coefficients 


$$
\begin{aligned}
& c+m_{y}=Y=A_{y} \min \left\{n_{y}, \frac{m_{h}}{\varepsilon_{y}}\right\}, \\
& h+m_{h}=H=A_{h} \min \left\{n_{h}, \frac{m_{y}}{\varepsilon_{h}}\right\} .
\end{aligned}
$$

The parameters $\varepsilon_{y} \geq 0$ and $\varepsilon_{h} \geq 0$ capture the intensity of the sectoral interlinkages.. Using the nonsubstitutability of inputs and the constraint on total employment yields a linear production possibility frontier:

$$
c+\left(\frac{A_{y}+\varepsilon_{h}}{A_{h}+\varepsilon_{y}}\right) h=\left(\frac{A_{y} A_{h}-\varepsilon_{y} \varepsilon_{h}}{A_{y}+\varepsilon_{h}}\right) n .
$$

To satisfy feasibility, it must be the case that $A_{y} A_{h}>\varepsilon_{y} \varepsilon_{h}$. If the intermediate input requirements are too high relative to the productivity of each sector, it would not be feasible to produce positive amounts of both goods. $\underline{10}$ The linearity of the production possibility frontier implies that the relative price of new houses depends only on the technical coefficients,

$$
p=\frac{A_{y}+\varepsilon_{h}}{A_{h}+\varepsilon_{y}} .
$$

In the model without interlinkages $\varepsilon_{j} \rightarrow 0$, the price is given by the ratio of productivities $p=A_{y} / A_{h}$. Similarly, wages are determined by

$$
w=\left(\frac{A_{y} A_{h}-\varepsilon_{y} \varepsilon_{h}}{A_{y}+\varepsilon_{h}}\right) .
$$

In the absence of sectoral shocks on $\left(A_{y}, A_{h}\right)$, exogenous changes in housing demand $(\Delta \theta)$ have no effect on prices and wages. All the macroeconomic effects of value added are driven by changes in the production of each sector:

$$
V A(\theta, \varepsilon)=c(\theta, \varepsilon)+\left(\frac{A_{y}+\varepsilon_{h}}{A_{h}+\varepsilon_{y}}\right) \cdot h(\theta, \varepsilon) .
$$

From this expression, it is direct to derive specifications for which a shift in housing demand is not amplified in the aggregate. The first one ignores sectoral interlinkages, $\varepsilon_{y}=\varepsilon_{h}=0$ as the model collapses to the standard two-sector model where relative prices are determined by factor productivities. The second one assumes perfectly symmetric sectors, $\varepsilon_{y}=\varepsilon_{h}=\varepsilon$ and $A_{y}=A_{h}=A$, implying steady-state prices and wages equal to $p=1$ and $w=(A-\varepsilon)$. One can easily add a third trivial case where the nonconstruction good is completely independent of $\theta$; that is, $c(\theta, \varepsilon)=c(\varepsilon)$.

Case 1: Preferences with Perfect Complementarity. This specification allows the housingdemand shifter $\Delta \theta$ to change directly the consumption demand of both goods. The utility index is given by $U(\theta c, h, n)=\min \{\theta c, h\}-a n^{1+\gamma} /(1+\gamma)$. This corresponds to the extreme case 
of perfect complementarity; but only some degree of complementarity (less than unitary elasticity of substitution between $c$ and $h$ ) is sufficient for the mechanism to operate. With this utility function consumption is given by

$$
\hat{c}=\left[\frac{A_{y} A_{h}-\varepsilon_{y} \varepsilon_{h}}{\left(A_{h}+\varepsilon_{y}\right)+\theta\left(A_{y}+\varepsilon_{h}\right)}\right] n,
$$

and the demand for housing is just $\hat{h}+\theta \hat{c}$. In the model without interlinkages $\left(\varepsilon_{j}=0\right)$, employment is allocated in the two sectors according to $\hat{n}_{h}^{\text {nolink }}=\left(A_{y} /\left(A_{y}+\theta A_{h}\right)\right) n$.

Solving for the aggregate level of employment yields

$$
\hat{n}^{\text {link }}=\left[\frac{\theta}{a}\left(\frac{A_{y} A_{h}-\varepsilon_{y} \varepsilon_{h}}{\left(A_{h}+\varepsilon_{y}\right)+\theta\left(A_{y}+\varepsilon_{h}\right)}\right)\right]^{\frac{1}{\gamma}},
$$

whereas in the absence of interlinkages the employment level is

$$
\hat{n}^{\text {nolink }}=\left[\frac{\theta}{a}\left(\frac{A_{y} A_{h}}{A_{h}+\theta A_{y}}\right)\right]^{\frac{1}{\gamma}} .
$$

Measured economic activity is given by

$$
V A=c+p h=\left[\frac{A_{y} A_{h}-\varepsilon_{y} \varepsilon_{h}}{A_{y}+\varepsilon_{h}}\right] \hat{n}^{i}(\theta) .
$$

Notice that value added is proportional to total employment, and the scaling factor does not depend on the parameter $\theta$. The change in value added due to a change in housing demand driven by $\Delta \theta$ is

$$
\frac{\partial V A}{\partial \theta}=\left[\frac{A_{y} A_{h}-\varepsilon_{y} \varepsilon_{h}}{A_{y}+\varepsilon_{h}}\right] \frac{\partial \hat{n}(\theta)}{\partial \theta} .
$$

We ask next, how do changes in the preference parameter $\theta$ affect aggregate employment, $n$, and value added, $V A$ ? Notice first, from the formulas above, that the economy with interlinkages and the one without them have different levels of aggregate employment. Hence, we will compute the two elasticities of employment with respect to variations in $\theta$.

In the economy with linkages, this elasticity is

$$
\epsilon_{n, \theta}^{\text {link }}=\frac{1}{\gamma}\left[\frac{A_{y}+\varepsilon_{h}}{\left(A_{h}+\varepsilon_{y}\right)+\theta\left(A_{y}+\varepsilon_{h}\right)}\right]>0,
$$

and in the economy without linkages it is

$$
\epsilon_{n, \theta}^{n o l i n k}=\frac{1}{\gamma}\left[\frac{A_{y}}{A_{h}+\theta A_{y}}\right]>0 .
$$


The presence of interlinkages amplifies the effect of any given preference shock when $\epsilon_{n, \theta}^{\text {link }}>\epsilon_{n, \theta}^{\text {nolink }}$, which reduces to $A_{h} \varepsilon_{h}>A_{y} \varepsilon_{y}$ after a bit of algebra. $\frac{11}{1}$ This condition is clearly satisfied when the construction sector purchases intermediate inputs from the rest of the economy $\left(\varepsilon_{h}>0\right)$, but not the other way around $\left(\varepsilon_{y}=0\right)$. Hence, in general, the condition holds (for given levels of sectoral productivities) when the construction sector absorbs lots of inputs from the other sector but the other sector does not use housing as an intermediate input, which does not sound so unrealistic. Notice that when there is symmetry between both sectors the condition fails. This is consistent with the earlier theoretical results of Horvath (1998) and Dupor (1999) cited in Section 2.

Is there some empirical evidence that supports this asymmetry? We have used the directinput requirement matrices to carry out a back-of-the-envelope test of these conditions. Our procedure was simple: We aggregated the matrices into a $2 \times 2$ format: construction and everything else. Next, we eliminated the "own intermediate inputs," which the model assumes away for simplicity, and collapsed all the value added of the two sectors into labor income. The sectoral price indices were used to compute the relative price $p$ during the available sample period and then to compute, by simple algebra, the four parameters of our model. We found that $A_{h} \varepsilon_{h} / A_{y} \varepsilon_{y}$ equals 636, after rounding up. The inequality is amply satisfied, thereby suggesting, on the basis of this admittedly simplified model, that in the real world the magnification effects of asymmetries are likely to be present.

Case 2: Preferences with Unitary Elasticity. To highlight the importance of the complementarity between $c$ and $h$, we consider the case of Cobb-Douglas preferences, $u(c, h)=\log c+\theta \log h$. This specification is very common in macro housing models (i.e., Davis and Heathcote, 2005, and Iacoviello, 2005) and in the recent literature on production networks (i.e., Acemoglu et al., 2012). It implies a total employment level

$$
\hat{n}=\omega^{i}((1+\theta) / a)^{\frac{1}{1+\gamma}}
$$

where $\omega^{\text {nolink }}=1$ in the economy without linkages and $\omega^{\text {link }}>1$ in the economy with them, independently of $\theta$. The level of aggregate employment is larger in the economy with linkages than in the one without them; but in response to changes in housing $(\Delta \theta)$, the two economies share the same aggregate labor elasticity,

$$
\epsilon_{n, \theta}^{\text {link }}=\epsilon_{n, \theta}^{n o l i n k}=\frac{1}{1+\gamma}\left(\frac{\theta}{1+\theta}\right) .
$$

Even with Leontief technologies, the unitary elasticity eliminates the contribution of the input-output multipliers. For this reason, in the quantitative exercise in Section 5, we explore the importance of demand complementarities by adopting a more general class of preferences that includes the Cobb-Douglas as a special case. 


\section{QUANTITATIVE ANALYSIS}

In this section we use the general model developed in the previous section to carry out various quantitative exercises.

\subsection{Parameterization}

To proceed we need to specify functional forms and then assign parameter values. The choice of functional forms is relatively general with the exception of the housing demand shifter,

$$
u\left(c_{t}, h_{t}, N_{t}\right)=\frac{\left[\eta c_{t}^{-\rho}+(1-\eta) h_{t}^{-\rho}\right]^{-\frac{1-\sigma}{\rho}}+\theta_{t} h_{t}}{1-\sigma}+\varrho \log \left(1-N_{t}\right)
$$

where the parameter $\rho$ controls the degree of demand complementarity between consumption, $c$, and housing services, $h$. The parameter $\sigma$ represents the intertemporal elasticity of substitution, and the parameter $\eta$ represents the relative importance of consumption. The utility from leisure is logarithmic, as is standard in the real business cycle literature with a representative agent. $\frac{12}{}$ Housing services enter as complementary to consumption goods but also as a linear term scaled by the parameter $\theta_{t}$ that shifts housing demand to generate a construction boom and bust. This is interpreted as a "reduced-form housing market wedge" given by $\tilde{\theta}_{t}$ that, when measured relative to consumption goods, implies the housing price equation

$$
p_{t}^{h}=R_{t}+\tilde{\theta}_{t}+\frac{p_{t+1}^{h}}{1+r_{t+1}}
$$

where the notion of rents comes from owner-equivalent rent given by

$$
R_{t}=\frac{(1-\eta)}{\eta}\left(\frac{c_{t}}{h_{t}}\right)^{1+\rho}
$$

Housing services are obtained from housing structures and land according to a CobbDouglas mixture,

$$
h=H(s, l)=z_{h}(s)^{\epsilon}(\bar{l})^{1-\epsilon},
$$

where $z_{h}$ represents a transformation factor between stock and flow. The production of the nonconstruction goods also uses a Cobb-Douglas technology:

$$
F\left(k, n^{y}, m^{y, y}, m^{s, y}\right)=A^{y}(k)^{\alpha_{1}}\left(n^{y}\right)^{\alpha_{2}}\left(m^{y, y}\right)^{\alpha_{3}}\left(m^{s, y}\right)^{1-\alpha_{1}-\alpha_{2}-\alpha_{3}},
$$

where $\alpha_{i}$ represents the share in production for input $i$. Notice that the specification allows for substitutability between intermediate goods. The technology used in the construction sector, instead, is a constant elasticity of substitution with diminishing returns to scale:

$$
G\left(n^{s}, m^{s, s}, m^{y, s}\right)=A^{s}\left[\gamma_{2}\left(n^{s}\right)^{-\gamma_{1} \gamma_{4}}+\left(1-\gamma_{2}\right)\left(\left(m^{s, s}\right)^{\gamma_{3}}\left(m^{y, s}\right)^{1-\gamma_{3}}\right)^{-\gamma_{4}}\right]^{-1 / \gamma_{4}} .
$$


Boldrin, Garriga, Peralta-Alva, Sánchez

\section{Table 2}

\section{Parameter Values}

\begin{tabular}{|c|c|c|c|c|c|c|c|c|c|c|c|c|c|c|}
\hline Parameter & $\alpha_{1}$ & $\alpha_{2}$ & $\alpha_{3}$ & $\gamma_{1}$ & $\gamma_{2}$ & $\gamma_{3}$ & $\gamma_{4}$ & $A^{y}$ & $A^{s}$ & $z_{h}$ & $\varepsilon$ & $\eta$ & $\sigma$ & $\rho$ \\
\hline Value & 0.18 & 0.50 & 0.035 & 0.62 & 0.40 & 0.04 & 1.5 & 2.4 & 1.74 & 0.175 & 0.28 & 0.435 & 1 & 5 \\
\hline
\end{tabular}

The model parameters are set to match long-run averages of their data counterparts between 1952 and 2000. The implied parameter values are relatively robust to the choice of the sample period; however, during the housing boom some of the ratios and long-run averages departed significantly from their historical trends. Hence, to avoid stacking the cards in favor of our model, we used data from only the period before the housing boom and bust to calibrate our model.

The time unit is a year, as input-output tables are yearly at best. The discount factor is $\beta=0.96$. The depreciation rates of residential structures and nonresidential capital are $\delta^{s}=0.015$ and $\delta^{y}=0.115$, respectively. The weight on leisure, $\varrho=0.33$, is such that total hours worked equal one-third of the time endowment in the steady state. The preference parameters are set to match the consumption-to-output and housing-to-output ratios. The parameters of the production functions are set to satisfy the following:

(i) the ratio of gross output in the two sectors, $Y^{s} / Y^{y}=0.08$;

(ii) the average labor share in the construction sector $=0.7$;

(iii) the average labor share in the nonconstruction sector $=0.65$;

(iv) the ratio of consumption to nonconstruction gross output $=0.35$;

(v) the observed shares of intermediates in gross output of own sector $\left(m^{y y}\right.$ and $\left.m^{s s}\right)$ $=0.4,0.007$;

(vi) time allocated to market activities, $n^{y}+n^{s}=1 / 3$; and

(vii) the ratio of employment in the two sectors, $n^{y} / n^{s}=16$.

The values of the parameters not listed here are displayed in Table 2. The intratemporal elasticity of substitution between consumption and housing services is determined by the parameter $\varepsilon_{c h}=1 /(1+\rho)$. Quantitatively, the value of $\rho$ is an important determinant of the spillover effects from housing into the rest of the economy. If consumption services are close substitutes, a decline in the demand for housing services can generate an increase in the demand for the consumption good; whereas if they are close complements, a decline in housing demand can translate into a decline also in the demand for consumption. Various recent papers, part of an extensive literature on the topic, estimate this elasticity to be less than 1. For example, Flavin and Nakagawa (2008) use a model of housing demand and estimate an elasticity of less than 0.2. Others (i.e., Song, 2010, and Landvoigt, 2017) use alternative model specifications and also estimate values for the elasticity to be less than 1 . The simulations consider elasticities $\varepsilon_{c h} \in\{0.17,0.25\}$.

To generate dynamics in housing demand and construction, households face unanticipated shocks to the demand shifter $\theta_{t}$. Households have some initial expectations about their 


\section{Figure 7}

\section{Dynamics of the Construction Sector: The Model and Data}
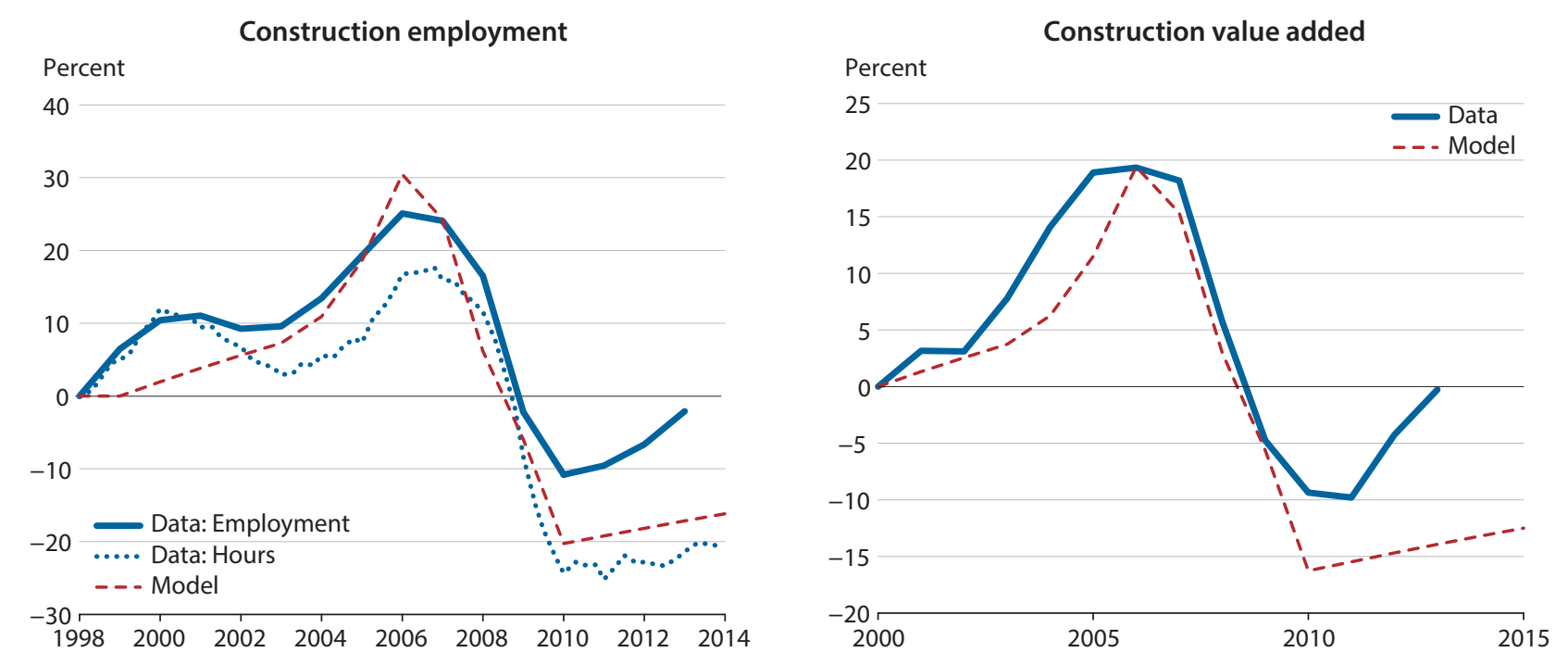

SOURCE: BEA and authors' calculations.

housing demand set by the initial values $\theta_{t}=\theta_{2000}$ for all $t \geq 2000$. Looking forward, they assume this parameter will remain unchanged in the future. In 2001, households are surprised by an initial increase in $\theta$ perceived as permanent going forward, $\theta_{t}=\theta_{2001}>\theta_{2000}$ for all $t \geq 2001$. In each subsequent period, this parameter is adjusted. In 2007, there is a demand reversal that generates a decline in housing demand until 2010; thereafter it remains constant forever. $\underline{13}$ The dynamics of this parameter are calculated to generate equilibrium paths of valued added and employment and hours in the construction sector that are in line with the data, as shown in Figure 7.

\subsection{Role of Residential Investment in Growth and Employment}

The goal of this exercise is to measure the sectoral contribution of the construction sector to the macroeconomy. The baseline case considers a boom and a bust in the construction sector, which generates the total employment and aggregate value-added series summarized in Figure 8. The shocks to the construction sector have nontrivial effects on total employment and aggregate value added. To measure the ability of the model to mimic the data, we measure the fraction of the changes in employment and GDP during the expansion period (2000-07) and during the recession (2007-10) it generates. During the boom, the exogenous changes in the demand for housing explain 60 percent of the change in total employment and 25 percent of value added. $\underline{14}$

Similarly, the housing crash, started by a sudden decrease in housing demand, generates declines in the employment of the construction sector and the demand for intermediate inputs 


\section{Figure 8}

\section{The Aggregate Implications of a Shock to Construction}

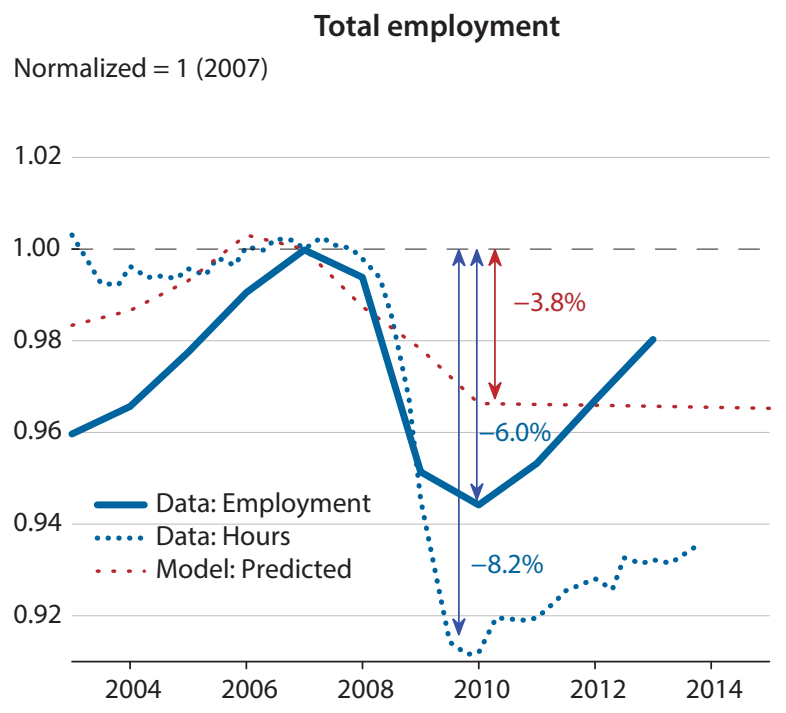

Aggregate value added (GDP)

Percent

5

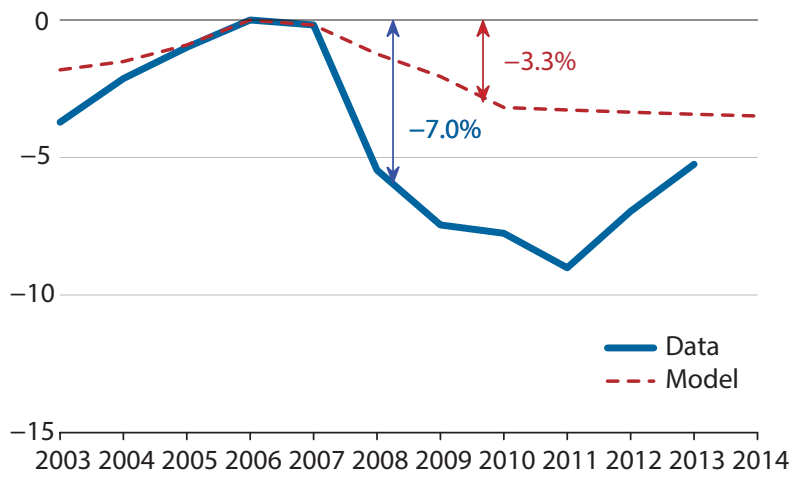

SOURCE: BEA and authors' calculations.

from suppliers. The input-output structure of the model once again lowers the demand for the nonconstruction sector as demand for intermediates from the construction sector falls. In the short run, the decline in the demand for housing generates a very small and short-lived increase in nonhousing consumption that is consistent with the empirical evidence, as shown in Figure 9. This temporary consumption increase is not sufficient to compensate for the decline in other key macroeconomic aggregates. In the model, the collapse of the construction sector (starting in 2007) generates a 3.8 percent decline in total employment and a 3.3 percent decline in aggregate value added. Comparing the numbers with the data, the model can rationalize 44 percent of the decline in employment and 56 percent of the decline in total value added.

An important feature of construction in the business cycle is its leading role during both booms and busts (see Leamer, 2007). Similarly, the data suggest that, during a boom, purchases of housing and durable goods increase faster than purchases of food and services; during a bust, purchases of housing and durable goods decline very sharply, while nonhousing related purchases continue to increase for a few more quarters. Our model captures these lead-lag patterns almost perfectly, as illustrated by the two panels of Figure 9.

In terms of prices, the model generates an 11 percent increase in the house price-to-rent ratio (price-rent ratio) during the housing boom and a 15 percent decline during the bust, as shown in the left panel of Figure 10. According to the OECD data, the price-rent ratio increased 40 percent during the boom and declined 25 percent during the bust. Relative to the data, the model captures around 30 percent of the boom and 60 percent of the bust. The model performs remarkably well given that this is a nontargeted moment and that there is only one force driving 


\section{Boldrin, Garriga, Peralta-Alva, Sánchez}

\section{Figure 9}

\section{Lead-Lag Responses of Consumption and Housing Spending}
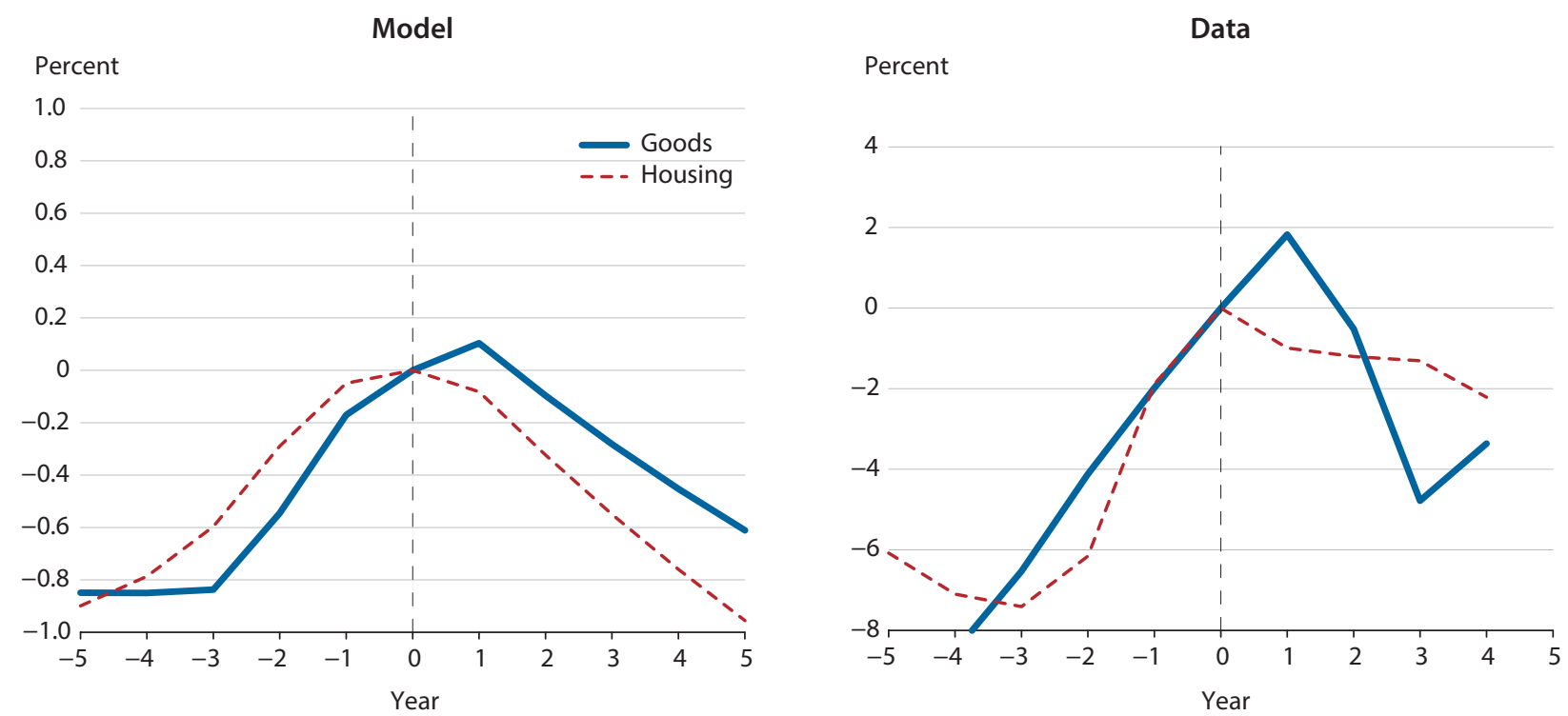

SOURCE: BEA and authors' calculations.

\section{Figure 10}

\section{Model-Implied Prices}
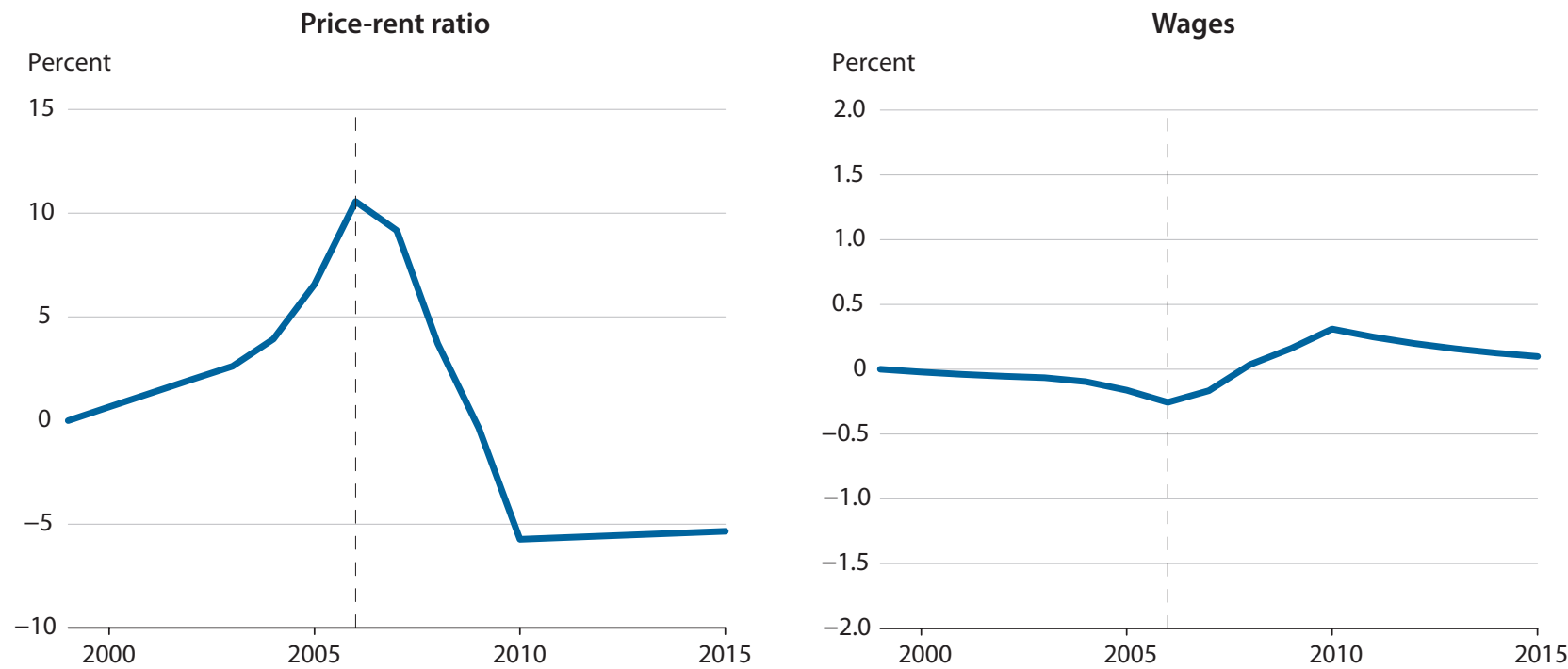

SOURCE: Authors' calculations 


\section{Figure 11}

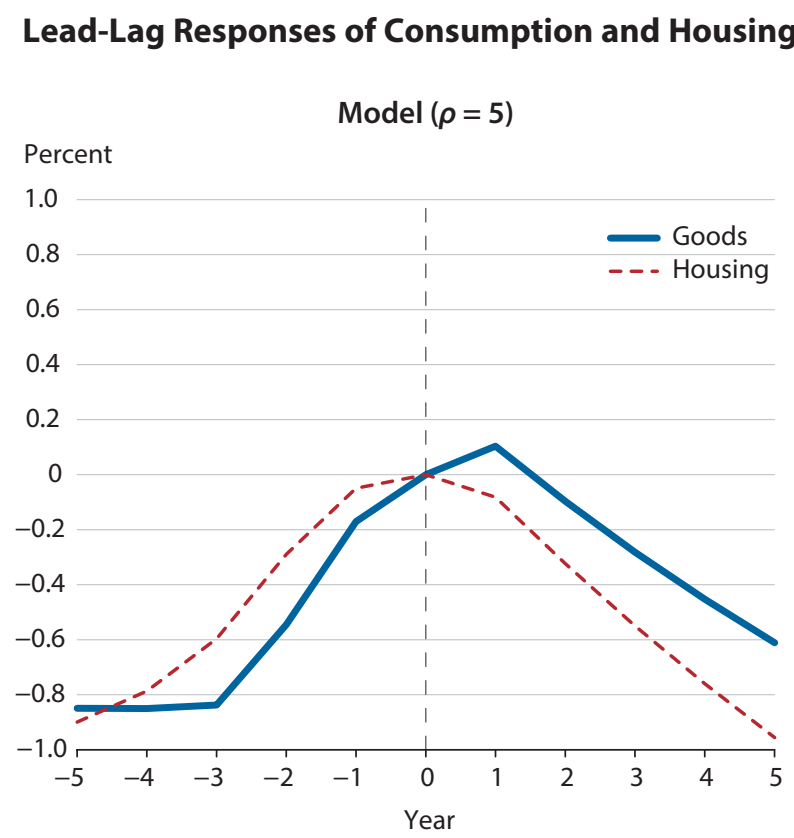

Model $(\rho=3)$

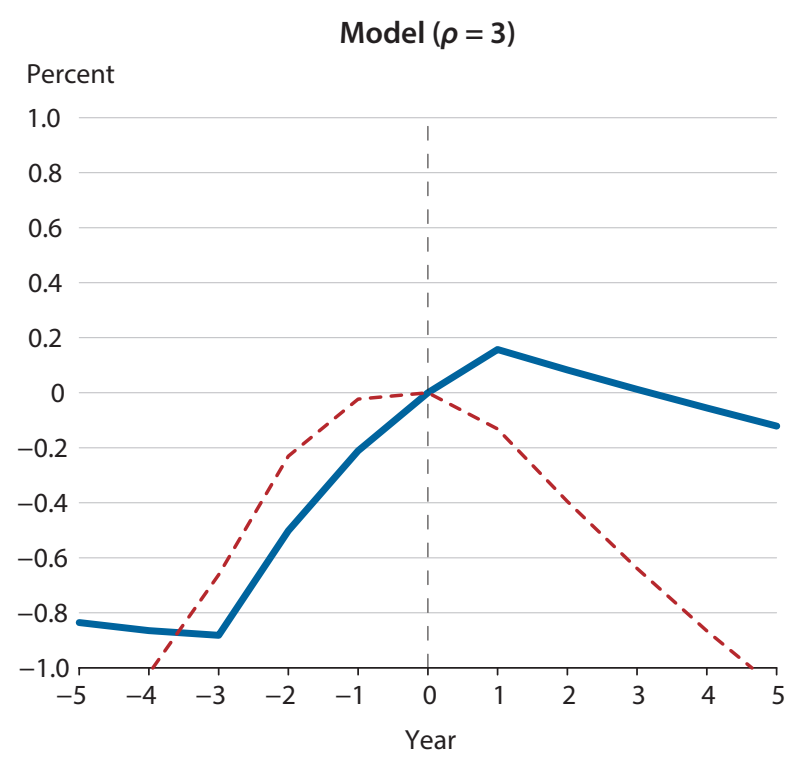

SOURCE: Authors' calculations.

the aggregate dynamics. For a detailed discussion on other drivers for house prices, see Garriga, Manuelli, and Peralta-Alva (2019).

The model can also reconcile large movements in employment and hours with very modest movements in real wages, as shown in the right panel of Figure 10. There is abundant research arguing that a variety of different frictions affecting the labor market are important to generate significant movements in aggregate employment (see, for example, Boldrin and Horvath, 1995; Christiano, Motto, and Rostagno, 2010; Arellano, Bai, and Kehoe, 2019; Gertler and Karadi, 2011; Hall, 2011; and Jones, Midrigan, and Philippon, 2018). Our model abstracts from such features, but modeling the use of intermediates allows us to reduce the response of wages to changes in the labor supply. Section 6 explores the connection of these findings with the existing literature.

\subsection{The Role of Demand Complementarities}

In our model, the complementarity between consumption and housing is an important driver of the employment dynamics. To compare the model implications for different levels of complementarity, we calculate, in each case, a sequence of demand shifters $\left\{\theta_{t}\right\}$ that match the dynamics of employment in the construction sector. The qualitative implications are the same, but the calibration with stronger complementarity generates a more pronounced boombust pattern. With a lower degree of complementarity, GDP falls 2 percent instead of 3.3 percent and total employment declines by 2.4 percent instead of 3.8 percent. The degree of complementarity also has implications for other variables. Figure 11 emphasizes the different 
lead-lag responses of consumption and housing spending. When the elasticity of substitution between consumption and housing is increased from 0.16 to 0.25 , consumption declines significantly less during a bust. With low elasticity, expenditures on goods respond with a lag relative to housing but have similar dynamics. As the elasticity increases, the dynamics of goods expenditures diverge from the declining path of housing. Increasing the elasticity to higher numbers $(\rho<2)$ would generate a boom of the nonconstruction sector during the collapse of the construction sector. A low elasticity of substitution magnifies the aggregate responses of employment and capital investment.

\subsection{The Role of Interlinkages and Supply Complementarities}

In our view the interlinkages have been an important driver of aggregate output and employment during the housing boom and bust. To isolate the effects of the interlinkages from those derived purely from consumer demand for housing, we study two alternative specifications. The first uses the same parametric calibration and shuts off interlinkages by holding the sectoral demand of intermediates fixed at the level of the initial steady state in $1998\left(m_{t}^{s, s}=m_{0}^{s, s}, m_{t}^{y, s}=m_{0}^{y, s}, m_{t}^{y, y}=m_{0}^{y, y}, m_{t}^{s, y}=m_{0}^{s, y}\right)$. This case is referred to as the "no interlinkages specification." The second formulation completely ignores the role of intermediate goods $\left(m_{t}^{s, s}=m_{t}^{y, s}=m_{t}^{y, y}=m_{t}^{s, y}=0\right)$, and the production functions are specified for value added and not gross output. $\frac{15}{1}$ In this "value-added specification," the relevant technologies ignore the use of intermediate inputs from other sectors in the economy. The nonconstruction sector satisfies

$$
c_{t}+x_{t}^{k}=A_{t}^{y} F\left(k_{t}, n_{t}^{y}\right)
$$

and the construction sector satisfies

$$
x_{t}^{h}=A_{t}^{s} G\left(n_{t}^{s}\right) .
$$

For both specifications, we carry out the same simulation experiment under the assumption that $\rho=5$. The housing demand shifter is adjusted to generate movements in construction employment consistent with the data. Figure 12 compares the key macroeconomic aggregates in the three cases: the baseline model with interlinkages, a specification with no interlinkages, and the value-added specification.

Consider first the case labeled "no interlinkages," which is simpler because the intermediates are fixed to the initial steady-state levels. Both sectors are committed to producing the same amount of intermediates every period. During the housing boom, the only way to produce more structures is to use more capital and labor. Since the quantity of intermediates cannot adjust, prices adjust more relative to the baseline level. Qualitatively speaking, the equilibrium dynamics of this version of the model are similar to those of the baseline one. However, the quantitative implications are very different. Since intermediates are constant, the marginal product of labor in the construction sector does not increase as much as in the baseline experiment and employment also does not increase as much either. The construction sector expands during the boom, but because the links to the other sector have been severed, 


\section{Figure 12}

\section{The Impact of Construction: Role of Interlinkages $(\rho=5)$}
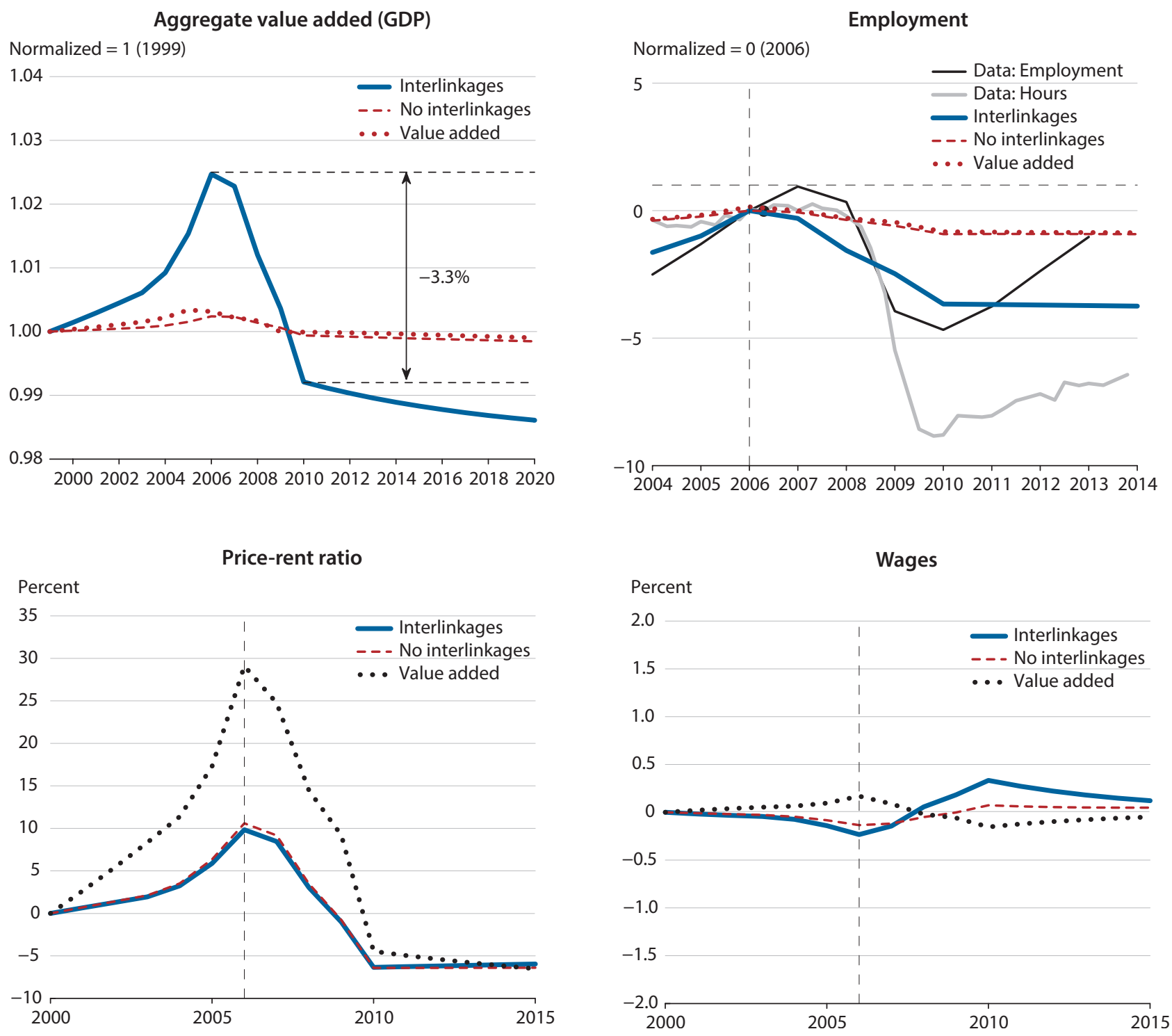

SOURCE: BEA and authors' calculations.

the latter barely moves in spite of the consumption complementarity: All movements are less than 0.5 percent. Consequently, the changes in GDP and employment are an order of magnitude smaller than in the economy with intersectoral links. The input-output links operate, de facto, as total factor productivity changes in the manufacturing sector, turning the variations in the demand for houses into a variation in the marginal value of output for the second sector. 


\section{Figure 13}

\section{Lead-Lag Responses of Consumption, Housing Spending, and Investment}
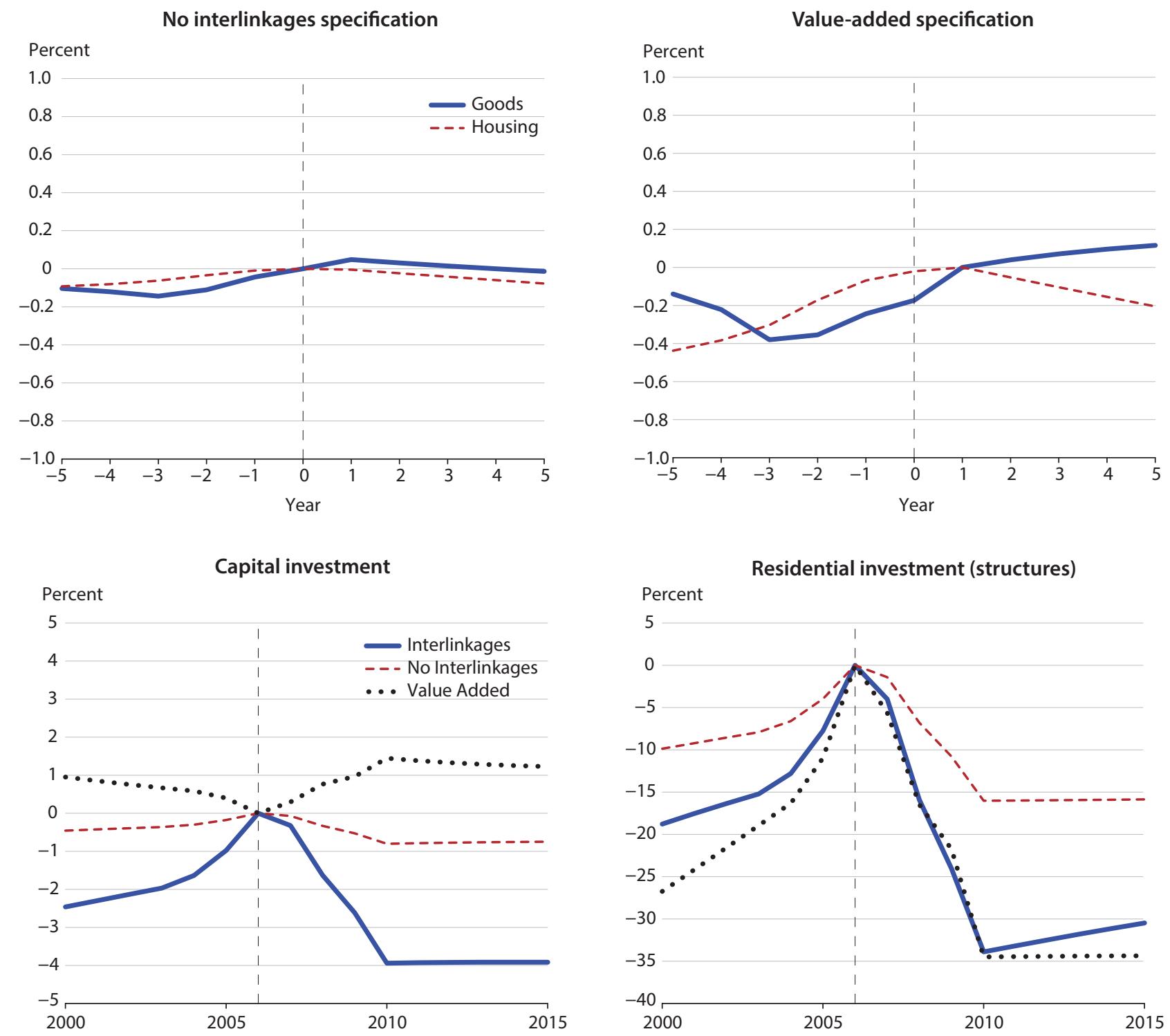

SOURCE: BEA and authors' calculations.

In the value-added model, the change in the demand for housing also generates very small booms and busts in output and employment. Here the propagation from housing to the rest of the economy travels only on the demand side (via consumption complementarity), and the effect is consequently small. For the value-added case, the adjustment via prices is more severe because the only way to prevent individuals from purchasing more housing is to increase house prices. In this case, the effects of a positive demand shock are a sizeable appreciation of 


\section{Table 3}

\section{Quantitative Implications of Alternative Models}

\begin{tabular}{lccccc} 
& \multicolumn{2}{c}{ Share of changes accounted for by the construction sector (percent) } \\
\cline { 2 - 3 } \cline { 5 - 6 } Experiment & \multicolumn{2}{c}{ Expansion 2000-07 } & & \multicolumn{2}{c}{ Recession 2007-10 } \\
\cline { 2 - 3 } \cline { 5 - 6 } Bemployment & GDP & & Employment & GDP \\
\hline Baseline $(\rho=5)$ & 60.2 & 25.3 & & 43.9 & 56.2 \\
\hline Lower complementarity $(\rho=3)$ & 28.7 & 14.1 & & 28.7 & 40.6 \\
\hline Value-added specific $(\rho=5)$ & 14.9 & 3.2 & & 14.5 & 8.5 \\
\hline No interlinkages specific $(\rho=5)$ & 14.5 & 2.5 & & 10.6 & 4.8 \\
\hline SOURCE: Authors' calculations. & & & & & \\
\hline
\end{tabular}

house values but small macroeconomic spillovers on the production side, as the construction sector is not directly interconnected with the rest of the economy. The adjustment in relative prices leads wages to remain relatively constant.

As shown in Figure 13, the responses of consumption, house spending, and investment are very different in each specification. In the model with fixed interlinkages, the dynamics are similar to those in the baseline model presented in Figure 9. However, the magnitudes are significantly smaller. The dynamics of the value-added specification are very different and resemble the case of high elasticity of substitution.

The study of these three alternative specifications illustrates an important point. The presence of interlinkages is necessary to generate large aggregate changes from fluctuations in construction. In fact, both alternative models generate very small changes in output and employment (for given shifts in the demand for housing) even though both maintain the complementarity between consumption and housing. Complementarity between housing and consumption, alone, delivers only very small aggregate fluctuations, which instead appear when the input-output structure of the economy is accounted for. Interlinkages are also crucial for the behavior of investment. In response to demand shocks, the model with interlinkages generates a simultaneous increase in consumption (housing and nonhousing) as well as investment (residential and nonresidential), whereas the value-added specification fails to account for such strong comovements. No asymmetric input-output structure, no business cycle action.

\subsection{Quantitative Implications of Alternative Models}

The different specifications studied lead to a general conclusion: The aggregate importance of the construction sector is significant despite its relatively small share in terms of employment and value added. Table 3 presents a summary of all the results discussed above. The table shows, for each of the model specifications considered, the fractions of the changes in employment and GDP accounted for by shocks to the construction sector during the expansion (2000-07) and the recession (2007-10). In light of the previous discussion, the numerical values should be easy to interpret at this point. The left side of Table 3 considers the role of the construction 
sector in the expansion. Regardless of the complementarity between housing and consumption goods, the model with interlinkages reveals that the construction sector accounts for a very significant share of the growth in total employment: between 29 and 60 percent. It also reveals that the contribution of construction to GDP is also much larger than its share: between 14 and 25 percent, which is somewhat smaller than its contribution to employment.

According to our model, the contribution of construction to employment and output was arguably even more important during the Great Recession. Depending on the specification, the decline in employment generated in the models with interlinkages is between 28 and 44 percent of the actual decline during the recession. In the case of GDP, the model generates between 41 and 56 percent of the observed changes. The model suggests that construction has been an important macroeconomic driver during the housing boom and bust and also highlights the asymmetry of its contribution between the expansion and the recession. During expansions the spillover on employment is larger than on output, but during recessions it is the opposite.

\section{INTERLINKAGES AND BUSINESS CYCLE ACCOUNTING}

An alternative methodology to identify the sources of economic fluctuations, within the context of a one-sector growth model, is "business cycle accounting," based on Chari, Kehoe, and McGrattan (2007). Recent works, including Arellano, Bai, and Kehoe (2019) and Ohanian and Raffo (2012), document that the Great Recession can be accounted for, mostly, by a worsening of labor market distortions. Both of these studies find that the labor wedge worsened by about 12 percent during the 2007-09 recession. Different explanations have been proposed to rationalize the measured increase in distortions in the labor market. For instance, Arellano, Bai, and Kehoe (2019) propose a model of imperfect financial markets and firm-level volatility. Such a model captures about half of the worsening in the labor wedge.

The wedge can be computed using data on employment, consumption, and wages generated by any model. It is defined as

$$
X_{t}=-\frac{U_{N_{t}}}{U_{C_{t}}} / w_{t},
$$

where $U_{N_{t}}$ is the marginal disutility measured at the aggregate level of employment, $U_{C_{t}}$ is the marginal utility of consumption measured at the aggregate level of consumption, and $w_{t}$ is the aggregate wage rate. Assuming wages are flexible and considering an aggregate CobbDouglas production function with capital share $\alpha$, the wage can be replaced with

$$
w_{t}=\frac{Y_{t}}{N}(1-\alpha)
$$

Furthermore, using a log utility function for consumption and the following function for the disutility of employment,

$$
U(N)=B \frac{N}{1+v}^{1+v}
$$




\section{Figure 14}

\section{Business Cycle Accounting of the Model with Interlinkages}
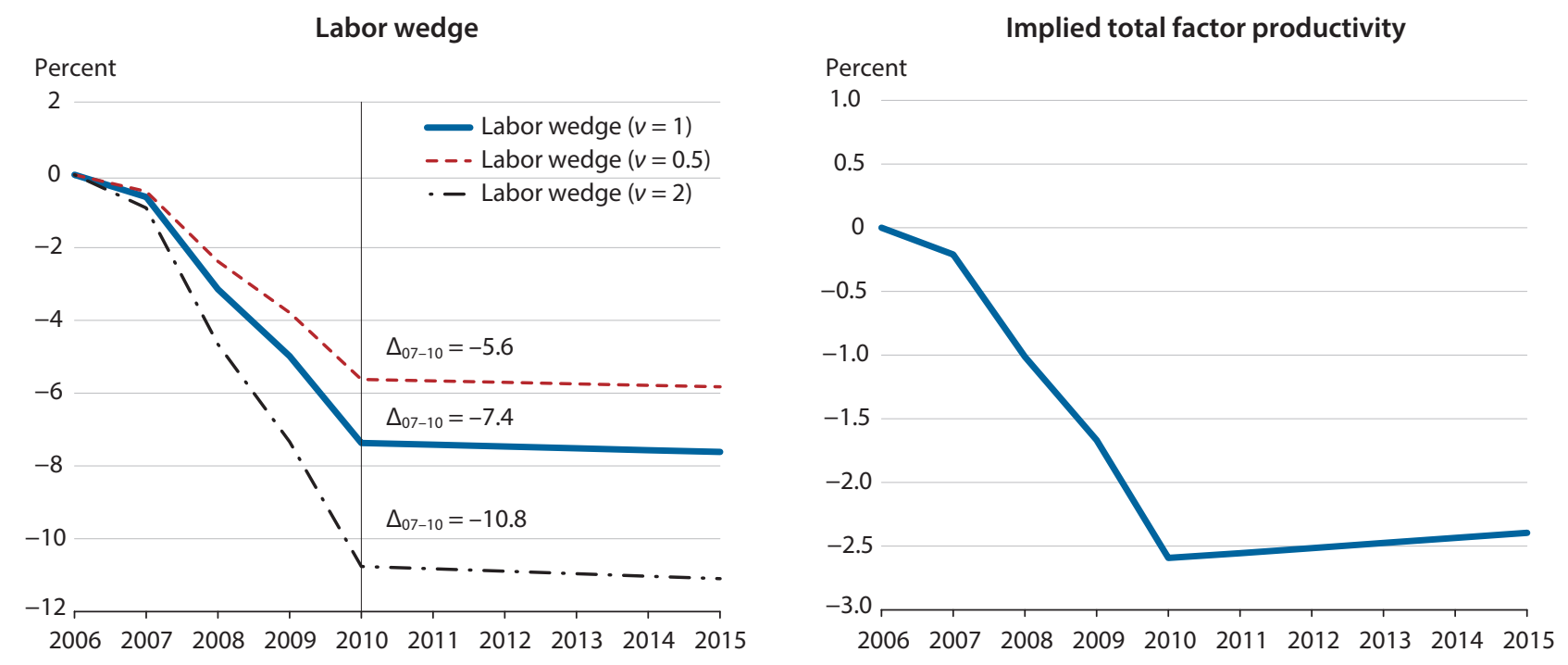

SOURCE: BEA and authors' calculations.

the wedge can be written as

$$
\Gamma_{t}=-\frac{B}{(1-\alpha)} \frac{C_{t}}{Y_{t}} N_{t}^{1+v}
$$

Notice that the parameters $B$ and $\alpha$ are not important to understand fluctuations in the labor wedge; only the time series for aggregate consumption, output, and employment, and a value for $v$, are required. We consider three values of $v=\{0.5,1,2\}$ and compute the labor wedge implied by our model using simulated data for consumption, output, and employment. Since our model has multiple sectors, several adjustments in the data are necessary. Consumption of goods and housing services are aggregated using relative prices $C_{t}=c_{t}+R_{t} h_{t}$. Aggregate output is $Y_{t}=C_{t}+X_{t}^{k}$, and total employment is $N_{t}=n_{t}^{y}+n_{t}^{s}$.

In the context of our model, any action in terms of implied distortions must be derived from the input-output structure and changes in relative prices. Figure 14 displays the changes in the labor wedge for our benchmark simulation. Its behavior is consistent with the data: The labor wedge worsens during the recession and does not recover quickly. For the case computed with $v=1$, which is consistent with the value used by Ohanian and Raffo (2012), the labor wedge worsens by 7.4 percent; this is about 62 percent of the total change in the labor wedge during this period. Notice that our computation of the labor wedge assumes that wages are perfectly flexible. If this condition does not hold, the labor wedge has another component, referred to as the "firm-side" labor wedge in Arellano, Bai, and Kehoe (2019). $\underline{16}$ This wedge is basically the difference between the marginal product of labor and the wage. These authors refer to the other component of the labor wedge as the "consumer-side" labor wage, which is 
basically our $\Gamma_{t}$. Arellano, Bai, and Kehoe (2019) find that (i) the firm-side labor wedge has been fairly flat since 2006 and (ii) a worsening of the consumer-side labor wedge accounts for most of the Great Recession. Recall that there are no frictions in our model, so wages equal the marginal product of labor in every period. Thus, not only the behavior of the labor wedge during the Great Recession but also its decomposition in the data are consistent with what our model predicts. It can also be shown that our model would be consistent with a large and fairly persistent negative shock to total factor productivity. The combination of these two would rationalize the model-predicted Great Recession.

\section{CONCLUSIONS}

This article analyzes the contribution of the construction sector to U.S. economic growth, particularly during the Great Recession, using a two-sector input-output model. Historically, the construction sector has been relatively small in terms of its contributions to employment and GDP, but it is highly interconnected with other sectors in the economy and highly volatile. Our empirical analysis reveals how these sectoral interlinkages propagate changes in housing demand, greatly amplifying their effect on the overall economy. In our model, construction accounts for 52 percent of the decline in employment and 35 percent of the decline in output during the Great Recession and for similar, albeit slightly smaller, shares during the preceding boom.

The importance of the sectoral interlinkages is illustrated first using a simple static multisector model. We prove that, in our model, changes in housing demand have a much larger effect on aggregate activity when the sectors are asymmetrically interconnected. Also, the presence of irreversibility constraints on investment introduces an asymmetry between the expansion and the recession in the dynamic model. The simulation exercise is calibrated to reproduce the boom-bust dynamics of construction employment in the period 2002-10. In the model, during the housing boom all sectors expand and contribute 2 percent and 2.5 percent to the growth of output and employment, respectively. During the housing bust, the irreversibility constraint binds, amplifying the asymmetric response: The declines in output and employment are 3.3 percent and 3.8 percent, respectively. With a lower degree of complementarity, the asymmetric effect is not as large but still significant. These numbers can be used to calculate the contribution of construction in the data. The model suggests that during the expansion (2002-07), the construction sector accounted for a significant share of the growth in employment (between 29 and 60 percent) and GDP (between 14 and 25 percent). The construction sector's contribution was more important during the Great Recession (2007-10): Our calibrated model suggests that movements in housing demand-propagating through the economy-accounted for 29 to 44 percent of the variation in aggregate employment and 41 to 56 percent of the variation in GDP.

The presence of intersectoral linkages substantially amplifies the impact of changes in housing demand. In the model specifications without this mechanism, changes in housing demand consistent with the dynamics in construction employment have only a small effect on macroeconomic quantities. This is true even when the complementarity between consump- 
tion goods and housing services is high. A direct implication of this result is that the presence of interlinkages is necessary to generate large aggregate variations from changes in construction, and a high degree of complementarity is not sufficient to obtain the propagation of adjustments in housing demand to the rest of the economy we obtained in our model. To capture the intricacies of this mechanism it is necessary to formalize the aggregate economy with a multisector model with asymmetric interlinkages.

Since in our model the equilibrium is efficient, the behavior of output is also the behavior of potential output. Taking into account that both output and potential output were affected during the Great Recession, we perform a business cycle accounting exercise on simulated data from the model using the now common "wedge" approach. Despite the lack of any friction or distortion, the data our model generates attribute the recession to a worsening in the labor wedge. The magnitude generated by the model accounts for 62 percent of the total change observed in the data. Clearly, in our model, the metrics of the wedge measures are explained by the fact that we account for sectoral linkages, irreversibilities, and the movements of relative prices between sectors; they are not explained by frictions. This approach shows how multi-sector models of the business cycle can improve, or at least challenge, our understanding of the factors driving aggregate fluctuations.

A direct policy implication of our findings is that the output gap could be lower than historical estimates suggest. The historical anomalies in the events that took place between 2007 and 2013 can be accounted for by the equally anomalous evolution of housing demand in the six years before 2007 and in those following it. As far as policy is concerned, the basic implication of our research is simple: Estimations of output gaps using pre-2007 trends, and aggregate one-sector models, may lead to misleading policy prescriptions.

\section{APPENDIX}

\section{A1 MICROFOUNDATIONS FOR THE HOUSING DEMAND SHIFTERS}

The modeling strategy used in the article uses changes in "effective" housing demand as the driver of the amplification mechanism that affects sectoral interlinkages. There are many potential drivers of the changes in housing demand during the period we study. This particular episode witnessed sizeable changes in home ownership and significant innovations in housing finance at the household level (i.e., new mortgage products) and the industry level (i.e., the use of mortgage-backed securities as a liquid asset). This section provides a microfoundation of housing demand shocks using two different specifications. The first one uses credit constraints in housing finance, where changes in collateral requirements (i.e., loan-to-value ratios) are isomorphic to variations in the relative weight that housing has on preferences (intensive margin). The second one considers the case where a large number of new households enter into the owner-occupied housing market. At the aggregate level this is also captured as an increase in the aggregate demand for housing (extensive margin). Either specification would be consistent with the approach used by Chari, Kehoe, and McGrattan (2007) that reduces all the frictions in the model to distortions/wedges in the equilibrium conditions. 


\section{A1.1 "Effective" Housing Demand and Credit Constraints}

The first specification relates housing demand to the presence of credit constraints. Consider a simple two-period version of the household optimization problem to allow for borrowing and collateral constraints of the form $b \leq \lambda p h$. This is the standard constraint that restricts the amount of housing finance to be proportional to the value of the house, $\lambda \in[0,1]$. The cost of borrowing, $R>1$, is paid in the second period and can differ from the return of other assets, $\frac{17}{r}$. For ease of exposition, consider the case where housing fully depreciates at the end of the second period and labor is inelastically supplied. The optimization problem of the representative consumer is

$$
\begin{array}{cc}
\max _{c_{1}, c_{2}, h, s, b} u\left(c_{1}\right)+\beta u\left(c_{2}\right)+\tilde{\theta} v(h), \\
\text { s.t. } \quad c_{1}+s+p h=w_{1}+b, \\
b \leq \lambda p h, \\
c_{2}=w_{2}+(1+r) s+b R .
\end{array}
$$

The optimality condition for housing measured in terms of $t=1$ consumption goods can be written as $\underline{18}$

$$
\theta \frac{v^{\prime}(h)}{u^{\prime}\left(c_{1}\right)}=p[1-\lambda(1+\phi)] .
$$

When the solution is interior, increases in the value of $\lambda$ reduce the cost of housing relative to the cost of consumption goods. This is observationally equivalent to an exogenous increase in $\theta$. Similarly, a tightening of credit conditions reduces housing demand. From this perspective, the relevant value is $\tilde{\theta}=\theta /[1-\lambda(1+\phi)]$. When housing finance is not present, $\lambda=0$, the expression for housing demand is the same as in the previous model and $\tilde{\theta}=\theta$.

\section{A1.2 "Effective" Housing Demand and Home Ownership}

Part of the housing boom was fueled by an increase in the home ownership rate. $\frac{19}{}$ The second specification relates the aggregate change in housing demand to increasing participation in the housing market, using a model based on Garriga, Manuelli, and Peralta-Alva (2019). Consider an economy where households are ex-ante heterogeneous in their labor ability $\varepsilon \in[\underline{\varepsilon}, \bar{\varepsilon}]$ and the ability distribution is uniform $\varepsilon \sim U(\underline{\varepsilon}, \bar{\varepsilon}) \equiv f(\varepsilon)$. Preferences are represented by a utility function $u(c, h)=c(\theta+h)$, where consumption goods are perfectly divisible, $c \in R_{+}$, and housing is a discrete good with only one size of home available, $h \in\{0, \bar{h}\}$. The implicit assumption is that renters consume zero housing and homeowners consume a fixed positive amount; we could allow for the purchase of different size homes at the cost of introducing unnecessary notation. The parameter $\theta>0$ can be interpreted as a reservation value for rental housing, and as $\theta \rightarrow 0$ owner-occupied housing becomes more desirable.

The optimization problem for the consumer is 


$$
\begin{gathered}
v(\varepsilon)=\max _{h}\left\{u^{r}\left(c^{r}, 0\right), u^{o}\left(c^{o}, \bar{h}\right),\right. \\
\text { s.t. } \quad c^{o}=w \varepsilon-(p \bar{h}+\phi), \\
c^{r}=w \varepsilon,
\end{gathered}
$$

where $w$ is the wage, $p$ is the house price, and the price of consumption goods is 1 . The term $\phi$ represents an exogenous transaction cost associated with buying a house, measured in terms of consumption goods. The optimal decision rule determines a cut-off level of ability necessary to purchase a house. For the specified preferences and under the necessary assumptions for an interior solution, the threshold for homeownership, $\varepsilon^{*}$, is characterized by

$$
\varepsilon^{*}(\theta, \bar{h}, \phi, p, w) \geq \frac{p}{w}(\theta+\bar{h})+\frac{\phi}{w \bar{h}} .
$$

In the model, the determinants of ownership are the cost of housing relative to income, $p / w$; the house size, $\bar{h}$; transaction costs, $\phi$; and the reservation value of rental housing, $20 \theta$. The comparative statics are straightforward. Increases in the house price, minimum house size, and transaction costs increase the income threshold required for home ownership, whereas an increase in wage income decreases it. Notice that the demand shifter changes the number of individuals buying houses, as the size of the latter is fixed.

Given this threshold, aggregate housing demand and the home ownership rate are in fact proportional:

$$
H(p)=\bar{h} \int_{\varepsilon^{*}}^{\bar{\varepsilon}} U(\underline{\varepsilon}, \bar{\varepsilon}) d \varepsilon=\frac{\bar{h}}{(\bar{\varepsilon}-\underline{\varepsilon})}\left[\bar{\varepsilon}-\frac{p}{w}(\theta+\bar{h})-\frac{\phi}{w \bar{h}}\right] .
$$

Despite its simplicity, the expression shows the connection between housing demand and the key individual variables. A reduction in the rental threshold, $\theta$, affects the total quantity demanded from the construction sector but also reduces the transaction costs, $\phi$, affecting housing demand.

\section{A2 ALTERNATIVE SPECIFICATIONS QUANTITATIVE MODEL: FIXED INTERLINKAGES AND VALUE-ADDED ECONOMIES}

In our quantitative analysis, we made an effort to disentangle the role of interlinkages. It is always challenging to compare different models, but the quantitative analysis suggests similar results from the various alternatives. The first alternative considers an economy calibrated to the same initial steady state (parameters and targets) and compares the economy with interlinked production with an economy where the amount of intermediates is fixed at the initial steady-state level. The second alternative compares the value-added economy with the linkage economy. Both are calibrated to the same target values for the baseline year, but the underlying parameters are different.

For a given sequence of land $\left\{\bar{l}_{t}\right\}_{t=0}^{\infty}$, there is an optimization problem that solves for the equilibrium in each case. In the baseline case with interlinkages, the social planner chooses a sequence of quantities $\left\{c_{t}, x_{t}^{k}, x_{t}^{s}, n_{t}^{y}, n_{t}^{s}, m_{t}^{s, s}, m_{t}^{y, s}, m_{t}^{y, y}, m_{t}^{s, y}\right\}_{t=0}^{\infty}$ to maximize 


$$
\begin{gathered}
\max \sum_{t=0}^{\infty} \beta^{t}\left[u\left(c_{t}, \theta_{t}, h_{t}\right)+\gamma v\left(1-n_{t}^{y}-n_{t}^{s}\right)\right], \\
\text { s.t. } \quad c_{t}+x_{t}^{k}+m_{t}^{y, y}+m_{t}^{y, s}=A_{t}^{y} F\left(k_{t}, n_{t}^{y}, m_{t}^{y, y}, m_{t}^{s, y}\right), \quad \forall t, \\
x_{t}^{s}+m_{t}^{s, s}+m_{t}^{s, y}=A_{t}^{s} G\left(n_{t}^{s}, m_{t}^{s}\left(m_{t}^{s, s}, m_{t}^{y, s}\right)\right), \quad \forall t, \\
x_{t}^{k}=k_{t+1}-\left(1-\delta_{k}\right) k_{t} \geq 0, \quad \forall t, \\
x_{t}^{s}=s_{t+1}-\left(1-\delta_{s}\right) s_{t} \geq 0, \quad \forall t, \\
h_{t}=H\left(s_{t}, \bar{l}\right), \quad \forall t, \\
s_{0}, k_{0} \geq 0 .
\end{gathered}
$$

In the model with no interlinkages, the production of intermediate goods is fixed at the steady-state level before the boom. In this case, the social planner is forced to produce the same quantity of intermediates each period $\left(m_{t}^{s, s}=m_{0}^{s, s}, m_{t}^{y, s}=m_{0}^{y, s}, m_{t}^{y, y}=m_{0}^{y, y}, m_{t}^{s, y}=m_{0}^{s, y}\right)$. To satisfy this constraint, the social planner picks a vector $\left\{c_{t}, x_{t}^{k}, x_{t}^{s}, n_{t}^{y}, n_{t}^{s}\right\}_{t=0}^{\infty}$ to maximize

$$
\begin{gathered}
\max \sum_{t=0}^{\infty} \beta^{t}\left[u\left(c_{t}, \theta_{t} h_{t}\right)+\gamma v\left(1-n_{t}^{y}-n_{t}^{s}\right)\right], \\
\text { s.t. } \quad c_{t}+x_{t}^{k}=A_{t}^{y} F\left(k_{t}, n_{t}^{y}, m_{0}^{y, y}, m_{0}^{s, y}\right)-\left(m_{0}^{y, y}+m_{0}^{y, s}\right), \quad \forall t, \\
x_{t}^{s}=A_{t}^{s} G\left(n_{t}^{s}, m_{0}^{s}\left(m_{0}^{s, s}, m_{0}^{y, s}\right)\right)-\left(m_{0}^{s, s}+m_{0}^{s, y}\right), \quad \forall t, \\
x_{t}^{k}=k_{t+1}-\left(1-\delta_{k}\right) k_{t} \geq 0, \quad \forall t, \quad \forall t, \\
x_{t}^{s}=s_{t+1}-\left(1-\delta_{s}\right) s_{t} \geq 0, \quad \forall t, \\
h_{t}=H\left(s_{t}, \overline{l_{t}}\right), \quad \forall t, \\
s_{0}, k_{0}, m_{0}^{s, s}, m_{0}^{y, s}, m_{0}^{y, y}, m_{0}^{s, y} \geq 0 .
\end{gathered}
$$

The last case studied is that of a value-added economy, where intermediate goods are completely eliminated. The social planner chooses a vector of quantities $\left\{c_{t}, x_{t}^{k}, x_{t}^{s}, n_{t}^{y}, n_{t}^{s}\right\}_{t=0}^{\infty}$ to maximize

$$
\begin{aligned}
& \max \sum_{t=0}^{\infty} \beta^{t}\left[u\left(c_{t}, \theta_{t} h_{t}\right)+\gamma v\left(1-n_{t}^{y}-n_{t}^{s}\right)\right], \\
& \text { s.t. } \quad c_{t}+x_{t}^{k}=A_{t}^{y} F\left(k_{t}, n_{t}^{y}\right), \quad \forall t, \\
& x_{t}^{s}=A_{t}^{s} G\left(n_{t}^{s}\right), \quad \forall t, \\
& x_{t}^{k}=k_{t+1}-\left(1-\delta_{k}\right) k_{t} \geq 0, \quad \forall t, \quad \forall t, \\
& x_{t}^{s}=s_{t+1}-\left(1-\delta_{s}\right) s_{t} \geq 0, \quad \forall t \\
& h_{t}=H\left(s_{t}, \bar{l}_{t}\right), \quad \forall t \\
& s_{0}, k_{0} \geq 0 .
\end{aligned}
$$




\section{A3 CALIBRATION OF INTERLINKAGES}

Interlinkages are calibrated using input-output data. In particular, the information shown in Table A1 is used to calibrate the parameters of the two production functions and is calculated from the BEA's 2010 use input-output table. The use table shows the uses of commodities by intermediate and final users; rows present the commodities or products, and columns display the industries and the final users. The sum of the entries in a row is the output of that commodity. The columns show the products consumed by each industry and the three components of value added - compensation of employees, taxes on production and imports less subsidies, and the gross operating surplus. Value added is the difference between an industry's output and the cost of its intermediate inputs; total value added is equal to GDP.

Table A1 displays input-output values (which are originally in millions of dollars) as a fraction of each industry's output. Construction receives most of its inputs from other industries (48.3 percent of its gross output) and less than 1 percent from itself. The reverse is true for the other industries, as they receive most of their inputs from themselves ( 43.0 percent of their total gross output).

\section{Table A1}

\section{Coefficients with Respect to Column Industries}

\begin{tabular}{lcc} 
Commodities/industries & Construction & Other industries \\
\hline Construction & 0.0009 & 0.0058 \\
\hline Other industries & 0.4828 & 0.4301 \\
\hline Compensation of employees & 0.3625 & 0.2802 \\
\hline Taxes on production and imports, less subsidies & 0.0072 & 0.0471 \\
Gross operating surplus & 0.1466 & 0.2368 \\
\hline Total & 1.0000 & 1.0000 \\
\hline SOURCE: BEA 2010 use input-output table. & & \\
\hline
\end{tabular}

\section{NOTES}

1 Davis and Heathcote (2005) construct a real business cycle with housing and interlinkages. In the baseline economy with Cobb-Douglas preferences, the presence of interlinkages generates a relatively small contribution to aggregate fluctuations in response to productivity shocks. Our theoretical model shows that Cobb-Douglas preferences completely eliminate the role of interlinkages because of insufficient complementarity. This is true even when the sectoral linkages are asymmetric. lacoviello (2005) generates house price fluctuations using shocks to Cobb-Douglas preferences, but the productive structure of the economy does not have interlinkages, so most of the action is driven by the presence of binding collateral constraints and price rigidities.

$\underline{2}$ The appendix provides two microfoundations for the drivers of housing demand. We show that this shock is isomorphic to a model that relaxes collateral constraints or a model with housing demand at the extensive margin.

3 The analysis abstracts from both the increase in the burden of debt brought about by the decline in home prices (which is the focus of Garriga, Manuelli, and Peralta-Alva, 2019) and the reduction in credit activity it implied, two factors that are likely to have played a major role in the overall process. Although these factors could interact with 


\section{Boldrin, Garriga, Peralta-Alva, Sánchez}

the sectoral interlinkages, abstracting from them captures the contribution of the real side of the economy in the recession.

4 It is often argued that the housing sector is of great relevance to the aggregate economy because housing wealth is a major determinant of consumption demand (see Carroll, Otsuka, and Slacalek, 2011; Case, Quigley, and Shiller, 2005; and Mishkin, 2007, which are among the most cited articles). An ample and somewhat more recent literature (e.g., Calomiris, Longhofer, and Miles, 2009, and lacoviello, 2011, and the references therein) has cast serious doubts on the quantitative relevance of this channel for business cycles analysis. While the housing sector is certainly very cyclical, this is most likely not due to a causal chain going from housing wealth to consumption and aggregate demand to output, but to a host of other common factors driving such comovements. Further, the same literature also reveals that, when empirical evidence of a causal link is found, the latter is not only quantitatively weak but its magnitude is also dependent on demographic and financial variables.

$\underline{5}$ The traditional view of the business cycle literature is that idiosyncratic sectoral shocks are likely to average out and have no aggregate effects as the number of sectors in the economy gets larger (i.e., Lucas, 1981; Kydland and Prescott, 1982; Long and Plosser, 1983; and Dupor, 1999).

6 In the analysis hereafter, the definition of the construction sector does not include the real estate and leasing sector, because the two sectors are quite different. Including it in the definition of the construction sector would substantially increase the construction sector's significance in accounting for the Great Recession.

$\underline{7}$ For employment, we use the employment requirements matrix from the Bureau of Labor Statistics (BLS).

8 For expositional purposes, in this section we assume that the diagonal coefficients of the requirement matrix $A$ in the Leontief model are zero. The general formulation would be $c+m_{y y}+m_{y h}=Y=A_{y} f\left(n_{y}, \varepsilon_{y y} m_{y y}, \varepsilon_{y h} m_{h y}\right)$ and $h+m_{h y}+m_{h h}=H=A_{h} g\left(n_{h}, \varepsilon_{h y} m_{y h}, \varepsilon_{h h} m_{h h}\right)$, where in each $m_{i j}$, the first subscript denotes the origin (i) and the second denotes the destination $(j)$.

9 As $\varepsilon_{j} \rightarrow 0$, the required quantity of the intermediate good converges to zero, $m_{j} \rightarrow 0$. When both coefficients converge to zero, the technologies become $c=A_{y} n_{y}$ and $h=A_{h} n_{h}$, respectively. In this case, the interlinkages disappear.

10 This condition is the well-known "all or nothing" property of Leontief input-output models. When it is met, the economy is productive and any nonnegative value added is reachable if enough labor input is available.

11 This condition is related to the irrelevance result in Dupor (1999).

12 This specification implies a Frisch elasticity of labor equal to 2. Keane and Rogerson (2012) argue that this elasticity can be reconciled with lower elasticity estimates at the micro level.

13 The long-run value of $\theta$ has small quantitative implications for the short-run dynamics discussed in this article.

14 The magnitudes of these numbers vary with the time interval considered, but the overall magnitudes are within reasonable bounds.

15 See the appendix for model details.

16 They follow Galí, Gertler, and López-Salido (2007) in this decomposition.

17 In this class of model, the consumer usually has an incentive to borrow to purchase the house when the cost of borrowing is lower than the return of other assets, $R / 1+r=\phi<1$ (additional conditions are discussed later in the article). In many countries, interest payments are tax deductible, reducing the effective cost of borrowing relative to other assets. Under this assumption, the Lagrange multiplier of the collateral constraint binds, and housing demand directly determines the amount of borrowing.

$\underline{18}$ For an interior solution with borrowing it suffices that $\lambda<1 /(1+\phi)$.

19 See Chambers, Garriga, and Schlagenhauf $(2009 a, b)$ for a detailed discussion on the home ownership rate boom between 1994 and 2007.

20 When the transaction cost is proportional to the value of the house, the budget constraint of the buyer is slightly different, $c^{o}=w \varepsilon-(p+\phi) \bar{h}$, and the homeownership threshold is $\varepsilon^{*} \geq \frac{(p+\phi)}{w}(\theta+\bar{h})$. 


\section{REFERENCES}

Acemoglu, Daron; Carvalho, Vasco M.; Ozdaglar, Asuman and Tahbaz-Salehi, Alireza. "The Network Origins of Aggregate Fluctuations." Econometrica, 2012, 80(5), pp. 1977-2016; https://doi.org/10.3982/ECTA9623.

Acemoglu, Daron; Ozdaglar, Asuman and Tahbaz-Salehi, Alireza. "Systemic Risk and Stability in Financial Networks." American Economic Review, 2015, 105(2), pp. 564-608; https://doi.org/10.1257/aer.20130456.

Arellano, Cristina; Bai, Yan and Kehoe, Patrick J. "Financial Frictions and Fluctuations in Volatility." Journal of Political Economy, October 2019, 127(5), pp. 2049-103; https://doi.org/10.1086/701792.

Atalay, Enghin; Dratzburg, Thorsten and Wan, Zhenting. "Accounting for the Sources of Macroeconomic Tail Risks." Economics Letters, April 2018, 165, pp. 65-69; https://doi.org/10.1016/j.econlet.2018.01.032.

Benhabib, J. and Nishimura, K. "On the Uniqueness of Steady States in an Economy with Heterogeneous Capital Goods." International Economic Review, 1979, 20(1), pp. 59-82; https://doi.org/10.2307/2526416.

Black, Fischer. "Interest Rates as Options." Journal of Finance, 1995, 50(5), pp. 1371-76; https://doi.org/10.1111/j.1540-6261.1995.tb05182.x.

Bloom, N. "The Impact of Uncertainty Shocks." Econometrica, 2009, 77(3), pp. 623-85; https://doi.org/10.3982/ECTA6248.

Boldrin, M. and Deneckere, R. "Sources of Complex Dynamics in Two-Sector Growth Models." Journal of Economic Dynamics and Control, 1990, 14, pp. 627-53; https://doi.org/10.1016/0165-1889(90)90036-G.

Boldrin, M. and Horvath, Michael. "Labor Contracts and Business Cycles." Journal of Political Economy, October 1995, 103(5), pp. 972-1004; https://doi.org/10.1086/262010.

Brunnermeier, Markus and Sannikov, Yuliy. "Reviving 'Money and Banking,'” in Lucrezia Reichlin and Richard Baldwin, eds., Is Inflation Targeting Dead? Centre for Economic Policy Research, 2013, pp. 95-101.

Caliendo, Lorenzo; Parro, Fernando; Rossi-Hansberg, Esteban and Sarte, Pierre-Daniel. "The Impact of Regional and Sectoral Productivity Changes on the U.S. Economy." NBER Working Paper 20168, National Bureau of Economic Research, 2014; https://doi.org/10.3386/w20168.

Calomiris, Charles; Longhofer, Stanley D. and Miles, William. “The (Mythical?) Housing Wealth Effect." NBER Working Paper 15075, National Bureau of Economic Research, 2009; https://doi.org/10.3386/w15075.

Campbell, Jeffrey R. and Hercowitz, Zvi. "The Role of Collateralized Household Debt in Macroeconomic Stabilization." NBER Working Papers 11330, National Bureau of Economic Research, 2005; https://doi.org/10.3386/w11330.

Carroll, Christopher D.; Otsuka, Misuzu and Slacalek, Jiri. "How Large Are Housing and Financial Wealth Effects? A New Approach." Journal of Money, Credit, and Banking, February 2011, 43, pp. 55-79; https://doi.org/10.1111/j.1538-4616.2010.00365.x.

Carvalho, Vasco M. "Aggregate Fluctuations and the Network Structure of Intersectoral Trade." Economics Working Papers, Department of Economics and Business, Universitat Pompeu Fabra, 2010.

Carvalho, Vasco M. and Gabaix, Xavier. "The Great Diversification and Its Undoing." American Economic Review, 2013, 103(5), pp. 1697-1727; https://doi.org/10.1257/aer.103.5.1697.

Case, Karl E.; Quigley, John M. and Shiller, Robert J. “Comparing Wealth Effects: The Stock Market Versus the Housing Market." Advances in Macroeconomics, 5(1), 2005; https://doi.org/10.2202/1534-6013.1235.

Chambers, Matthew; Garriga, Carlos and Schlagenhauf, Don. "Accounting for Changes in the Homeownership Rate." International Economic Review, 2009a, 50(3), pp. 677-726; https://doi.org/10.1111/j.1468-2354.2009.00544.x.

Chambers, Matthew S.; Garriga, Carlos and Schlagenhauf, Don. "The Loan Structure and Housing Tenure Decisions in an Equilibrium Model of Mortgage Choice." Review of Economic Dynamics, 2009b, 12(3), pp. 444-68; https://doi.org/10.1016/j.red.2009.01.003.

Chari, V.V.; Kehoe, P.J. and McGrattan, E.R. "Business Cycle Accounting." Econometrica, 2007, 75(3), pp. 781-836; https://doi.org/10.1111/j.1468-0262.2007.00768.x.

Christiano, Lawrence J.; Motto, Roberto and Rostagno, Massimo. "Financial Factors in Economic Fluctuations." European Central Bank working paper, May 2010. 


\section{Boldrin, Garriga, Peralta-Alva, Sánchez}

Davis, Morris A. and Heathcote, Jonathan. "Housing and the Business Cycle." International Economic Review, 2005, 46(3), pp. 751-84; https://doi.org/10.1111/j.1468-2354.2005.00345.x.

Davis, Morris A and Van Nieuwerburgh, Stijn. "Housing, Finance and the Macroeconomy." Handbook of Urban and Regional Economics, 2015, 5, pp. 753-811; https://doi.org/10.1016/B978-0-444-59531-7.00012-0.

Dupor, Bill. "Aggregation and Irrelevance in Multi-Sector Models." Journal of Monetary Economics, April 1999, 43(2), pp. 391-409; https://doi.org/10.1016/S0304-3932(98)00057-9.

Fisher, Jonas D.M. "Why Does Household Investment Lead Business Investment Over The Business Cycle?" Journal of Political Economy, 2007, 115(1), pp. 141-68; https://doi.org/10.1086/511994.

Flavin, Marjorie and Nakagawa, Shinobu. "A Model of Housing in the Presence of Adjustment Costs: A Structural Interpretation of Habit Persistence." American Economic Review, March 2008, 98(1), pp. 474-95; https://doi.org/10.1257/aer.98.1.474.

Foerster, Andrew T.; Sarte, Pierre-Daniel G. and Watson, Mark W. "Sectoral Versus Aggregate Ahocks: A Structural Factor Analysis of Industrial Production." Journal of Political Economy, 2011, 119(1), pp. 1-38; https://doi.org/10.1086/659311.

Gabaix, Xavier. "The Granular Origins of Aggregate Fluctuations." Econometrica, 2011, 79(3), pp. 733-72; https://doi.org/10.3982/ECTA8769.

Galí, J.; Gertler, M. and López-Salido, J.D. "Markups, Gaps, and the Welfare Costs of Business Fluctuations." Review of Economics and Statistics, 2007, 89(1), pp. 44-59; https://doi.org/10.1162/rest.89.1.44.

Garriga, Carlos; Chambers, Matthew and Schlagenhauf, Don. "Did Housing Policies Cause the Postwar Boom in Homeownership?" NBER Working Paper 18821, National Bureau of Economic Research, 2012; https://doi.org/10.20955/wp.2012.021.

Garriga, Carlos; Manuelli, Rodolfo and Peralta-Alva, Adrian. "A Macroeconomic Model of Price Swings in the Housing Market." American Economic Review, 2019, 109(6), pp. 2036-72; https://doi.org/10.1257/aer.20140193.

Gertler, Mark and Karadi, Peter. "A Model of Unconventional Monetary Policy." Journal of Monetary Economics, 2011, 58(1), pp. 17-34; https://doi.org/10.1016/j.jmoneco.2010.10.004.

Gervais, Martin. "Housing Taxation and Capital Accumulation." Journal of Monetary Economics, 2002, 49(7), pp. 1461-89; https://doi.org/10.1016/S0304-3932(02)00172-1.

Hall, R.E. "The Long Slump." American Economic Review, 2011, 101, pp. 431-69; https://doi.org/10.1257/aer.101.2.431.

$\mathrm{He}$, Zhiguo and Krishnamurthy, Arvind. "A Macroeconomic Framework for Quantifying Systemic Risk." American Economic Journal: Macroeconomics, October 2019, 11(4), pp. 1-37; https://doi.org/10.1257/mac.20180011.

Herkenhoff, Kyle F. and Ohanian, Lee E. "Foreclosure Delay and U.S. Unemployment." Working Paper 2012-017, Federal Reserve Bank of St. Louis, 2012; https://doi.org/10.20955/wp.2012.017.

Herkenhoff, Kyle F. and Ohanian, Lee E. "Labor Market Dysfunction During the Great Recession." Cato Papers on Public Policy, July 2011, 1; https://doi.org/10.3386/w17313.

Horvath, Michael. "Cyclicality and Sectoral Linkages: Aggregate Fluctuations from Independent Sectoral Shocks." Review of Economic Dynamics, 1998, 1(4), pp. 781-808; https://doi.org/10.1006/redy.1998.0028.

Horvath, Michael. "Sectoral Shocks and Aggregate Fluctuations." Journal of Monetary Economics, 2000, 45(1), pp. 69-106; https://doi.org/10.1016/S0304-3932(99)00044-6.

lacoviello, Matteo. "House Prices, Borrowing Constraints, and Monetary Policy in the Business Cycle." American Economic Review, June 2005, 95(3), pp. 739-64; https://doi.org/10.1257/0002828054201477.

lacoviello, Matteo. "Housing Wealth and Consumption." International Finance Discussion Paper No. 1027, Board of Governors of the Federal Reserve System, 2011; https://doi.org/10.17016/IFDP.2011.1027.

lacoviello, Matteo and Pavan, Marina. "Housing and Debt Over the Life Cycle and Over the Business Cycle." Journal of Monetary Economics, 2013, 60(2), pp. 221-38; https://doi.org/10.1016/j.jmoneco.2012.10.020.

Jermann, Urban and Quadrini, Vincenzo. "Erratum: Macroeconomic Effects of Financial Shocks." American Economic Review, 2012, 102(2), p. 1186; https://doi.org/10.1257/aer.102.2.1186. 
Boldrin, Garriga, Peralta-Alva, Sánchez

Jones, Callum; Midrigan, Virgiliu and Philippon, Thomas. "Household Leverage and the Recession." NBER Working Paper 16965, National Bureau of Economic Research, June 2018.; https://doi.org/10.5089/9781484373866.001.

Keane, Michael and Rogerson, Richard. "Micro and Macro Labor Supply Elasticities: A Reassessment of Conventional Wisdom." Journal of Economic Literature, June 2012, 50(2), pp. 464-76; https://doi.org/10.1257/jel.50.2.464.

Kehoe, Timothy J.; Ruhl, Kim J. and Steinberg, Joseph B. "Global Imbalances and Structural Change in the United States." NBER Working Paper 9339, National Bureau of Economic Research, August 2013; https://doi.org/10.3386/w19339.

Kocherlakota, N. "Incomplete Labor Markets." Working paper, Federal Reserve Bank of Minneapolis, 2012; https://www.minneapolisfed.org/article/2012/incomplete-labor-markets.

Kydland, Finn E. and Prescott, Edward C. "Time to Build and Aggregate Fluctuations.” Econometrica, 1982, pp. 1345-70; https://doi.org/10.2307/1913386.

Leamer, Edward E. "Housing Is the Business Cycle." NBER Working Papers 13428, National Bureau of Economic Research, 2007; https://doi.org/10.3386/w13428.

Li, Nan and Martin, Vance L. "Real Sectoral Spillovers: A Dynamic Factor Analysis of the Great Recession." Journal of Monetary Economics, November 2019, 107, pp. 77-95; https://doi.org/10.1016/j.jmoneco.2018.10.002.

Long, John B. Jr. and Plosser, Charles I. "Real Business Cycles." Journal of Political Economy, 1983, pp. 39-69; https://doi.org/10.1086/261128.

Lucas, Robert E. Studies in Business-Cycle Theory. MIT Press, 1981.

Martinez, Leonardo; Hatchondo, Juan Carlos and Sánchez, Juan M. "Mortgage Defaults." Journal of Monetary Economics, 2015, 76, pp. 173-90; https://doi.org/10.1016/j.jmoneco.2015.09.011.

Mishkin, Frederic S. "Housing and the Monetary Transmission Mechanism." NBER Working Paper 13518, National Bureau of Economic Research, 2007; https://doi.org/10.3386/w13518.

Mitman, Kur; Kaplan, Greg and Violante, Gianluca. "The Housing Boom and Bust: Model Meets Evidence." Journal of Political Economy (forthcoming).

Ohanian, L.E. and Raffo, A. "Aggregate Hours Worked in OECD Countries: New Measurement and Implications for Business Cycles." Journal of Monetary Economics, 2012, 59(1), pp. 40-56; https://doi.org/10.1016/j.jmoneco.2011.11.005.

Rognlie, Matthew; Shleifer, Andrei and Simsek, Alp. "Investment Hangover and the Great Recession." American Economic Journal: Macroeconomics, 2018, 10(2), pp. 113-53; https://doi.org/10.1257/mac.20160211. 
